\author{
Article \\ Doi 10.5943/mycosphere/9/2/6 \\ Copyright $(\mathcal{C}$ Guizhou Academy of Agricultural Sciences
}

\title{
Myxomycete diversity in Costa Rica
}

\author{
Rojas $\mathbf{C}^{1,2^{*}}$, Rojas PA ${ }^{1}$ and Lado $C^{3}$
}

${ }^{1}$ Engineering Research Institute (INII), University of Costa Rica, San Pedro de Montes de Oca, 11501-Costa Rica
${ }^{2}$ Experimental Interdisciplinary Station of Agroecological Models (FEIMA), University of Costa Rica, Turrialba,
30502-Costa Rica
${ }^{3}$ Real Jardín Botánico (CSIC), Plaza de Murillo 2, 28014 Madrid - Spain

Rojas C, Lado C, Rojas PA 2018 - Myxomycete diversity in Costa Rica. Mycosphere 9(2), 227255, Doi 10.5943/mycosphere/9/2/6

\begin{abstract}
An updated analysis of myxomycete diversity in Costa Rica is provided herein as a product of an extensive data mining-based study intended to normalize the information on myxomycetes from that country. Within the context of the Mesoamerican Biodiversity Hotspot, the 242 species of myxomycetes are reported herein demonstrated the potential of this area for diversity-based studies. For the construction of the updated species list, a thorough analysis that included examination of vouchers and a literature review has been carried out, and some species previously included in other works have been rejected due to inconsistencies or misidentification. The present contribution is essential to address the Wallacean shortfall within Mesoamerica and important for providing updated data on microorganisms in the context of regional biodiversity monitoring.
\end{abstract}

Key words - Amoebozoa - biogeography - Central America - checklist - distribution myxogastrids - Myxomycetes - plasmodial slime moulds

\section{Introduction}

The myxomycetes of Costa Rica have been the subject of recent small-scale analyses (e.g., Rojas \& Doss, 2013, Rojas \& Valverde 2015, Lado \& Rojas, in rev.) and the last overall assessment of the diversity in this country, based on morphospecies, reported 208 species for the entire territory (Rojas et al. 2010a). This value represented about $48 \%$ of the total myxomycete diversity in the Neotropics at that time (see Lado \& Wrigley de Basanta 2008) and demonstrated that for this group of organisms, a small country can have a high number of species. In fact, a posterior analysis of myxomycete diversity in one well-studied 1500 ha patch of land in the same country yielded 85 species (Walker et al. 2015b), providing more support for such idea.

Costa Rica is one the jurisdictions with high myxomycete diversity within the Mesoamerican Biodiversity Hotspot, a region located between Southern Mexico and Northern Colombia. This result is a consequence of uneven efforts to study myxomycetes across the region and it does not show actual distributional patterns. However, it demonstrates the regional potential for comparative purposes. For instance, it has been acknowledged that this hotspot may contain up to $10 \%$ of the global biodiversity and just in the case of myxomycetes, understudied at the regional level, results have shown the region to have up to $24 \%$ of the accepted species worldwide (see Lado \& Eliasson 2017). 
In this sense, the systematic ongoing effort to study myxomycetes in Costa Rica during the last decade, which has increased the number of species in the country (Rojas 2017), has been an important contribution towards understanding myxomycete distribution in Mesoamerica. However, a review of the reported myxomycetes for the country had not been carried out yet due to inconsistencies in the information associated with records. As a strategy to address this problem, the present study has been designed within the framework of updating data on biological species for biodiversity conservation purposes (see Margules et al. 2002). As such, the main objective of the study presented herein was to generate an updated list of myxomycete species known from Costa Rica and to provide an overview of the documented diversity within administrative and bioclimatic regions. These analyses can show the accomplishments and shortcomings of myxomycete research within a spatial and temporal context.

\section{Materials \& Methods}

This study was carried out in the Royal Botanical Gardens of Madrid and the Engineering Research Institute at the University of Costa Rica during the years 2016 and 2017. As part of an initiative of the Myxotropic project (www.myxotropic.org), a creation and standardization of a database containing basic information on Costa Rican myxomycetes was carried out. For this, records were retrieved from the database created by Rojas et al. (2010a) and updated with information from the Farlow Herbarium (F) at Harvard University (USA), the Mycological Herbarium (UARKM) of the University of Arkansas (USA), the Botanische Staatssammlung München - Herbarium (M) from Germany where the collection of Martin Schnittler is deposited, the National Herbarium (CR) of Costa Rica, the herbarium of the University of Costa Rica (USJ), and the Myxogastrid Biorepository at the Engineering Research Institute (INII, University of Costa Rica).

After standardization of information, all records in the database were cross-checked with external databases such as GBIF (www.gbif.org) and the Neotropical myxomycete bibliographic database maintained, at the Real Jardín Botánico (CSIC), by the Myxotropic project. Vouchers deposited in the National Herbarium of Costa Rica, the University of Costa Rica Herbarium and the Myxogastrid Biorepository, which accounted for about $70 \%$ of all records in the database, were physically checked for information confirmation. After this process, a preliminary list of myxomycetes following the nomenclatural treatment of Lado (2006-2017) was generated and species were revised for inconsistencies. When records and species were flagged due to anomalous information, they were reviewed more thoroughly either by 1) physically revising the vouchers or 2 ) reviewing the literature where primary information was retrieved from. After this process, seven previously reported species for Costa Rica were excluded from the list provided herein, and a consolidated checklist was generated.

Collecting information for all species has been updated in the present study and included as annotations to the species list. In this manner, province, substrate type and forest type where all records have been found were incorporated after the species name. Provinces of Costa Rica are San José (coded with number 1), Alajuela (2), Cartago (3), Heredia (4), Puntarenas (5), Guanacaste (6) and Limón (7). Substrates were classified based on Rojas et al. (2014) as bark and wood (abbreviated as BW), ground litter (GL), aerial litter (AL), flowers and inflorescences (FI), fruits (FR), lianas (LI), living cryptogams (LC), living plants (LP), twigs (TW) and dung (DU). Forest type classification used the Holdridge system (Holdridge 1967) as Tropical Dry Forest (abbreviated as TDF), Tropical Moist Forest (TMF), Premontane Moist Forest (PMF), Lower Montane Moist Forest (LMF), Tropical Wet Forest (TWF), Premontane Wet Forest (PWF), Lower Montane Wet Forest (LWF), Montane Wet Forest (MWF), Premontane Rain Forest (PRF), Lower Montane Rain Forest (LRF), Montane Rain Forest (MRF) and Subalpine Rain Paramo (SRP). In addition, herbaria or collection where vouchers were deposited has been indicated using the acronym of the institution (see above).

The distribution of species within the Mesoamerican and Caribbean bioregions, arranged by countries, was generated. For practical purposes, the entire territories of Mexico, Colombia and 
Venezuela were included, since sections of those countries are located within such biogeographical regions (Fig. 1). The geographical criteria on small Caribbean islands provided by Lado \& Wrigley de Basanta (2008) in their review of Neotropical myxomycetes was also followed in the present study. The latter publication and a series of subsequent reports published by different authors on the regional countries considered herein (see Estrada-Torres et al. 2009, Izarduy et al. 2009, Montes 2009, Moreno et al. 2009, 2010, Rojas et al. 2010a, b, c, d, 2012, 2013, 2015a, b, c, 2017, Poulain et al. 2011, Agra et al. 2014, Leontyev et al. 2014, 2015, Rojas \& Calvo 2014, Rojas \& Doss 2014, Salazar-Márquez et al. 2014, Walker et al. 2014, 2015a, b, Lizárraga et al. 2015a, b, c, Rojas \& Valverde 2015, Dagamac et al. 2017) has been used to update the distribution of all species.

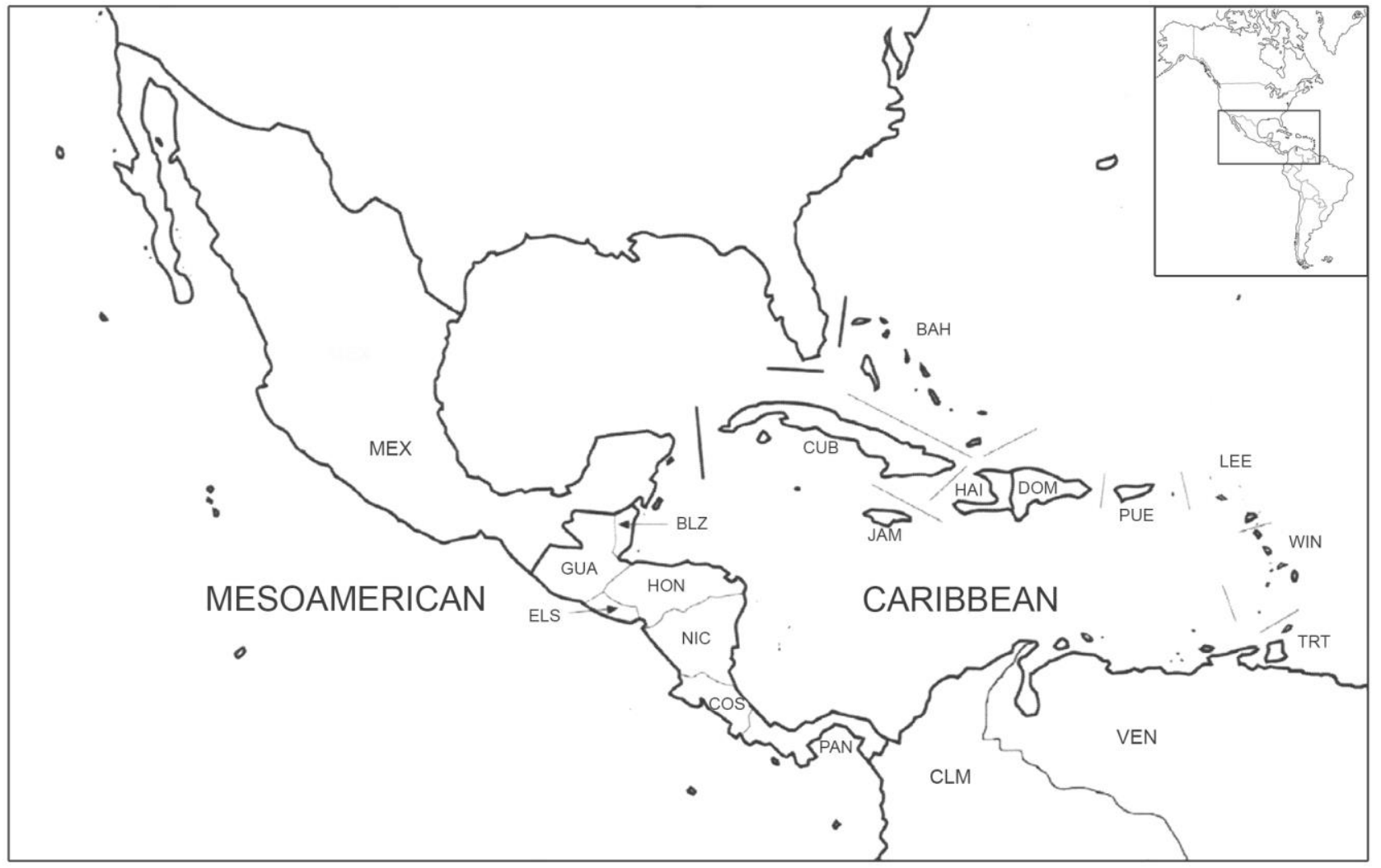

Figure 1 - Map of Mesoamerican and Caribbean countries. Mexico (MEX), Belize (BLZ), Guatemala (GUA), Honduras (HON), El Salvador (ELS), Nicaragua (NIC), Costa Rica (COS), Panama (PAN), Colombia (CLM), Venezuela (VEN), Trinidad and Tobago (TRT), Windward Islands (WIN), Leeward Islands (LEE), Puerto Rico (PUE), Dominican Republic (DOM), Haiti (HAI), Jamaica (JAM), Cuba (CUB), Bahamas (BAH).

Other annotations were provided for selected species whose vouchers were not found but for which reliable information was available, or for species not previously included in Rojas et al. (2010a). In the first case, comments on vouchers and collection information that was not easily available were included. In the second, in addition to the information provided for all species, a reference to the publication listing the species was added at the end.

A spatial analysis of diversity and collecting effort, based on species richness, relative abundance of collections and the Shannon-Wiener Diversity Index was generated for both 1) the province and canton-level administrative units of Costa Rica and 2) the climatic zones and Holdridge forest types of this country. With such analysis, a series of maps was generated in QGIS, v 2.18 (QGIS Development Team 2004-2014) for quick visual interpretation. Finally, a series of $\beta$ diversity calculations were carried out using Whittaker's Species Turnover Estimator (Whittaker 1960), defined by $\beta=(S / \bar{\alpha})-1$, where $S$ is total species richness and $\bar{\alpha}$ is the average number of species. 


\section{Results}

A total of 242 species of myxomycetes within 40 genera were recognized in Costa Rica according with a database of more than 7800 records compiled during this study. Seven species previously reported for this country have been rejected as not present in its territory due to lack of verifiable information or misidentifications. The comments on these species are provided below, in a different item section.

The province with the most myxomycete records was Puntarenas, and the one with the lowest number was Alajuela (see Table 1). Despite this, the average rate of species accumulation was 0.12 species per record in the latter and just 0.07 species per record in the former. Only weak correlations between province size and any of the estimators calculated herein were calculated,

Table 1 Calculated Costa Rican myxomycete diversity and collecting effort estimators arranged by province, based on the general database created as part of the present investigation.

\begin{tabular}{lcccc}
\hline Province & $\begin{array}{c}\text { Species } \\
\text { richness }\end{array}$ & $\begin{array}{c}\text { Number of } \\
\text { records }\end{array}$ & $\begin{array}{c}\text { Shannon-Wiener } \\
\text { Diversity Index }\end{array}$ & $\begin{array}{c}\text { Province } \\
\text { size }\left(\mathrm{km}^{2}\right)\end{array}$ \\
\hline Alajuela & 46 & 386 & 2.95 & 9757 \\
Cartago & 90 & 1179 & 3.45 & 3125 \\
Guanacaste & 118 & 1269 & 3.96 & 10141 \\
Heredia & 111 & 1226 & 3.65 & 2657 \\
Limón & 78 & 859 & 3.55 & 9189 \\
Puntarenas & 127 & 1762 & 3.65 & 11265 \\
San José & 128 & 1181 & 4.15 & 4966 \\
\hline
\end{tabular}

suggesting that sampling had not been homogeneous across provinces. This was particularly clear in the case of the province of Alajuela, one of the largest in area, where only 46 myxomycetes have been recorded. The highest Shannon-Wiener Index of Diversity was associated with San José and the lowest with Alajuela in a similar manner to species richness (Fig. 2).

When the analysis was performed by cantons, Sarapiquí and La Cruz showed the highest species richness, whereas the lowest recorded richness was existed for Montes de Oro y Vásquez de Coronado. The highest average rate of species accumulation was found in Santa Cruz and León Cortez. No correlations between canton size and the calculated estimators were found, suggesting one more time that the effort to study these administrative units has not been homogeneous. The highest values for the Shannon-Wiener Index of Diversity were found in La Cruz, Perez Zeledón, Puntarenas and Sarapiquí (Fig. 3).

When the analyses were performed by climatic zone and forest type (life zones) results showed that the wet zone of the Southern Pacific, the temperate Talamanca Mountains and the northern Isla Calero zone (Fig. 4) had the highest average value for the Shannon-Wiener Index of Diversity. In a similar manner, when the analysis was carried out using the Holdridge life zone classification, the highest average values for Shannon's Index were associated with the same areas in addition to some locations in the Northern Plains and the Guanacaste Mountain Range (Fig. 5). In this case, wet forests at the basal, premontane and lower montane elevational belts were identified to have the highest diversity. Interestingly, in both cases, the lowest average values were found in areas of the southern portion of the Alajuela Province, suggesting that under sampling was responsible for this result.

An analysis of $\beta$-diversity carried out among all provinces in the country showed that the two pairs of provinces with the most similar regional-to-local ratios of species richness were Guanacaste and Puntarenas $(\beta=0.29)$ along with Guanacaste and Heredia $(\beta=0.31)$. In this case, the overall $\beta$-diversity for the entire country was 1.31 . Similarly, when this analysis was carried out by cantons, the three units with the highest ratio of species richness were Jiménez and Puriscal $(\beta=0.20)$, Acosta and Puriscal $(\beta=0.26)$ and Bagaces and Sarapiquí $(\beta=0.29)$. The overall $\beta$ - 
diversity for cantons was calculated in 10.22, due to the rather low numbers of species for most of these administrative units.

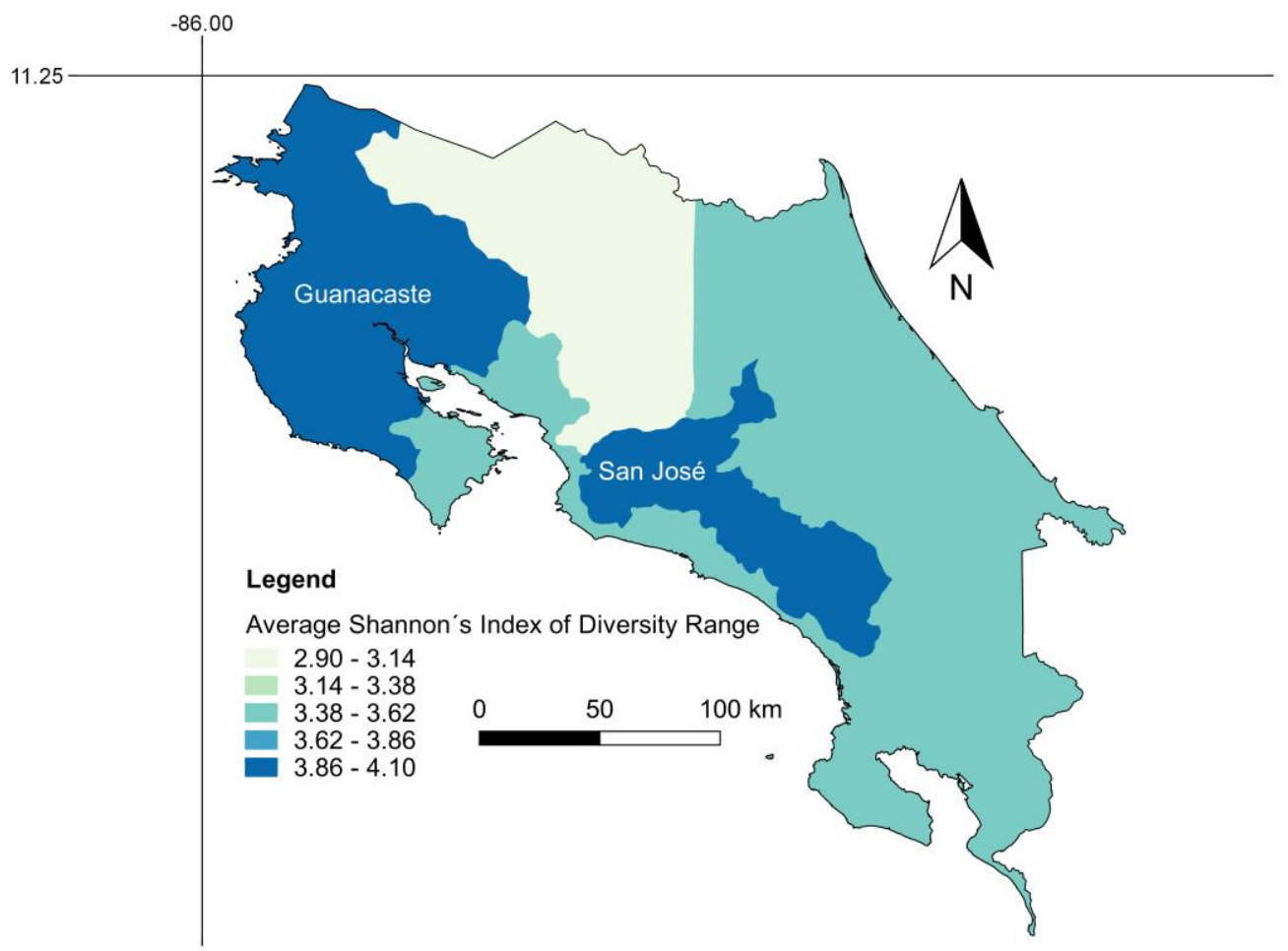

Figure 2 - Map of Costa Rica showing the spatial arrangement of provinces colored according to the average values of the Shannon-Wiener Index of Diversity using the myxomycete information of the present study. The two provinces with the highest values are shown.

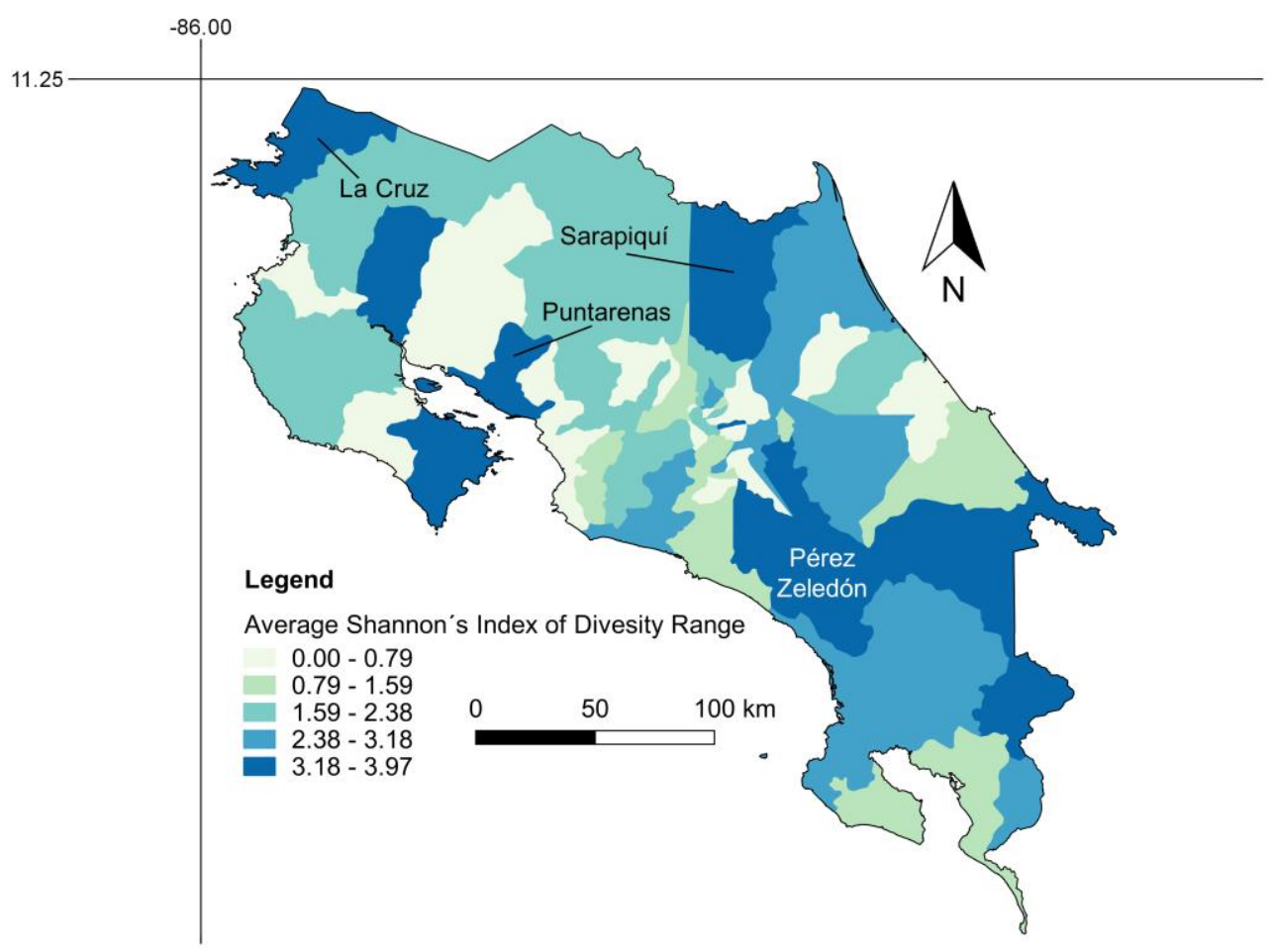

Figure 3 - Map of Costa Rica showing the spatial arrangement of cantons according to the Shannon-Wiener Index of Diversity using the myxomycete information of the present study. The four cantons with the highest values are shown. 


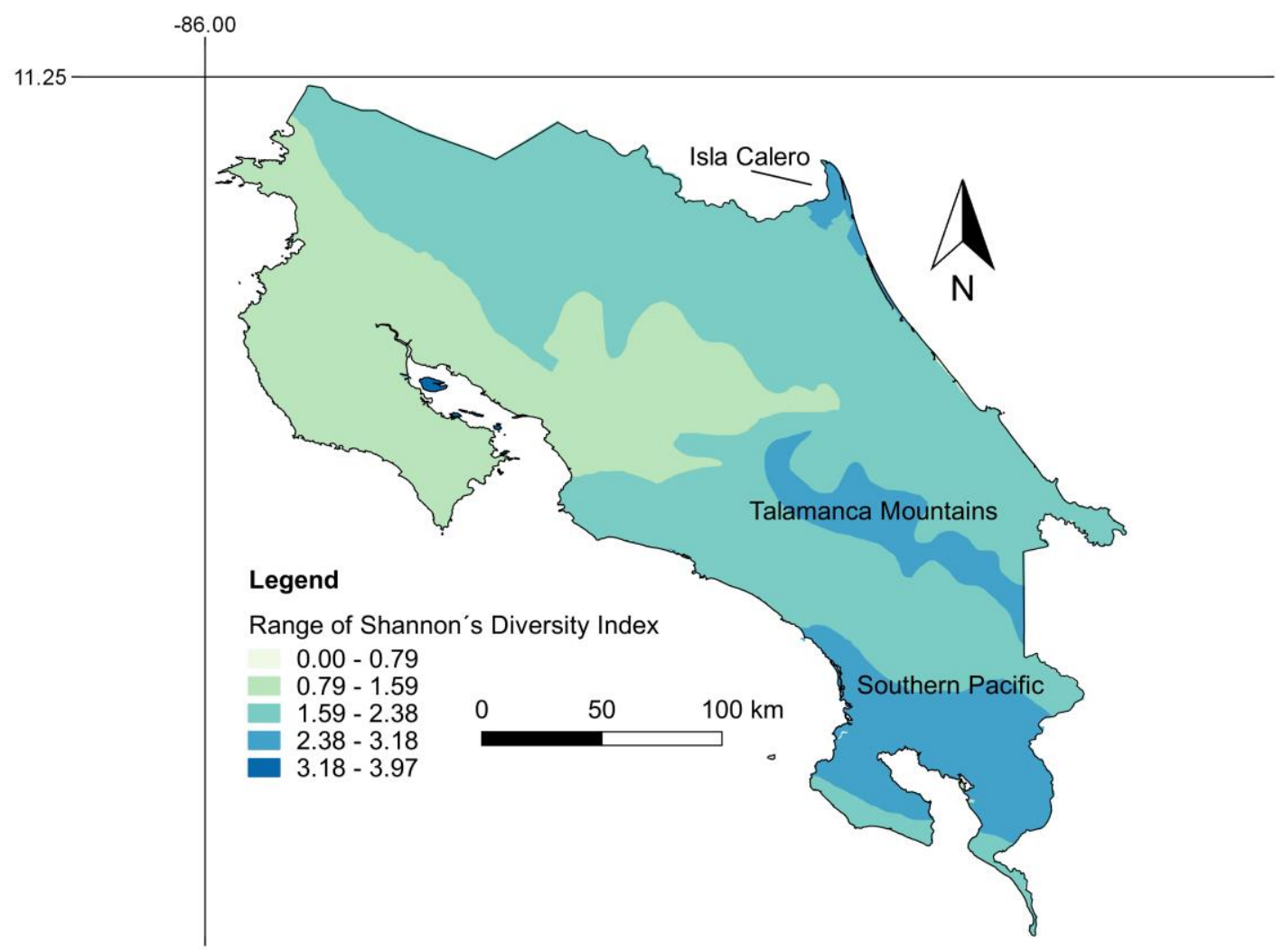

Figure 4 - Map of Costa Rica showing the spatial arrangement of the Shannon-Wiener Index of Diversity according to the natural borders defined by climate regions.

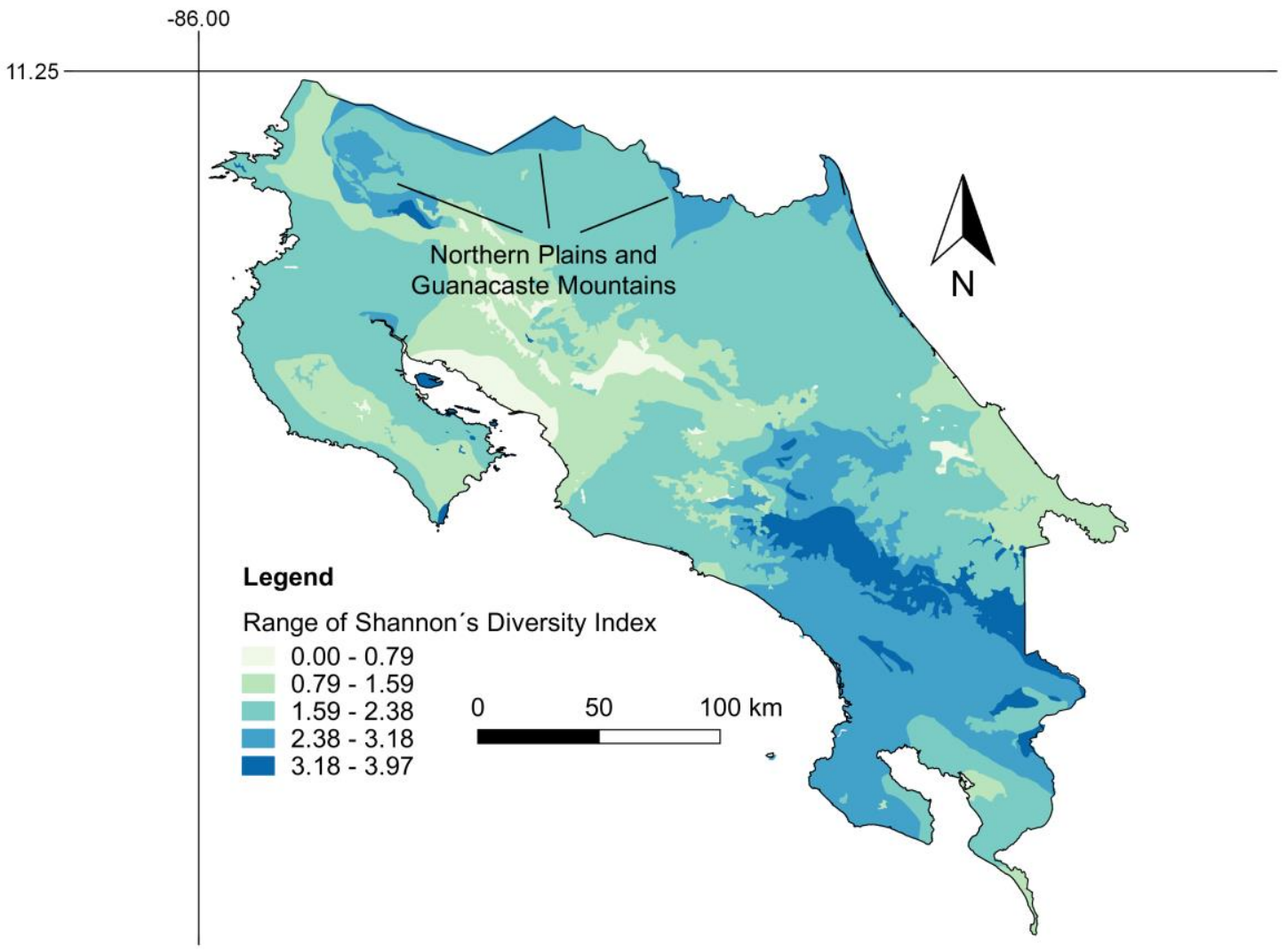

Figure 5 - Map of Costa Rica showing the spatial arrangement of the Shannon-Wiener Index of Diversity according to the natural borders defined by the Holdridge Life Zones. 
The complete depurated list of myxomycetes, with the information and criteria mentioned above, and in a synthetic format, is provided below.

\section{Annotated list of myxomycetes known from Costa Rica}

1. Alwisia bombarda Berk. \& Broome, 1873

Recorded in 4 and 5. On GL, DU. In PWF, PRF, LRF. Vouchers in M, USJ. Distribution:

Costa Rica, Jamaica, Puerto Rico and Venezuela.

2. Alwisia morula G. Moreno, Leontyev, D.W. Mitch., S.L. Stephenson, C. Rojas \& Schnittler,

2014

Recorded in 1. On BW. In LRF. Vouchers in M and USJ. Not known from other areas in

Mesoamerica and the Caribbean. Reported from Costa Rica by Leontyev et al. (2014).

3. Arcyria afroalpina Rammeloo, 1981

Recorded in all provinces. On GL, AL. In TDF, TMF, PMF, LMF, TWF, PWF, PRF, SRP.

Vouchers in M, UARKM, CR, USJ, INII. Distribution: Costa Rica, Cuba, El Salvador,

Guatemala, Honduras, Mexico, Panama, Puerto Rico.

4. Arcyria cinerea (Bull.) Pers., 1801

Recorded in all provinces. On BW, GL, AL, FI, LC, TW. In TDF, TMF, PMF, LMF, TWF,

PWF, LWF, PRF, LRF, MRF, SRP. Vouchers in F, M, UARKM, CR, USJ, INII.

Distribution: Bahamas, Costa Rica, Cuba, Dominican Republic, Guatemala, Haiti, Honduras,

Jamaica, Leeward Islands, Mexico, Nicaragua, Panama, Puerto Rico, El Salvador, Trinidad and Tobago, Venezuela, Windward Islands.

5. Arcyria denudata (L.) Wettst., 1886

Recorded in all provinces. On BW, GL, LC, DU. In TDF, TMF, PMF, LMF, TWF, PWF, LWF, PRF, LRF, MRF. Vouchers in F, M, UARKM, CR, USJ, INII. Distribution: Bahamas, Belize, Colombia, Costa Rica, Cuba, Dominican Republic, Honduras, Jamaica, Leeward Islands, Mexico, Nicaragua, Panama, Puerto Rico, El Salvador, Trinidad and Tobago, Venezuela, Windward Islands.

6. Arcyria globosa Schwein., 1822

Recorded in 3. On GL, In PWF. Vouchers in INII. Distribution: Colombia, Costa Rica, Cuba,

Mexico, Puerto Rico. Reported from Costa Rica by Rojas et al. (2017).

7. Arcyria incarnata (Pers. ex J.F. Gmel.) Pers., 1902

Recorded in 1, 2, 5 and 6. On BW, GL, TW. In TDF, TMF, PMF, PWF, MRF, SRP. Vouchers in F, UARKM, CR, USJ, INI. Distribution: Colombia, Costa Rica, Cuba, Haiti, Jamaica, Leeward Islands, Mexico, Puerto Rico, Trinidad and Tobago, Venezuela, Windward Islands.

8. Arcyria insignis Kalchbr. \& Cooke, 1882

Recorded in all provinces. On BW, GL, AL, FI, LP. In TDF, TMF, PMF, TWF, PWF, LRF. Vouchers in M, UARKM, CR, USJ, INII. Distribution: Colombia, Costa Rica, Cuba, Honduras, Jamaica, Leeward Islands, Mexico, Panama, Puerto Rico, Trinidad and Tobago, Venezuela.

9. Arcyria magna Rex, 1893

Recorded in 1. On BW. In PFM. Vouchers in UARKM, CR, USJ. Distribution: Costa Rica,

Cuba, Mexico, Panama, Windward Islands.

10. Arcyria minuta Buchet, 1927

Recorded in 4 and 5. On BW, TW. In PRF, LRF. Vouchers in M, CR. Distribution: Costa

Rica, Mexico, Panama.

11. Arcyria obvelata (Oeder) Onsberg., 1979

Recorded in 6. On BW. In TDF. Vouchers in CR. Distribution: Colombia, Cuba, Costa Rica,

Jamaica, Leeward Islands, Mexico, Panama, Trinidad and Tobago, Venezuela.

12. Arcyria pomiformis (Leers) Rostaf., 1875

Recorded in 1, 3 and 5. On BW, GL, AL. In PMF, TWF. Vouchers in UARKM, CR, INII.

Distribution: Colombia, Costa Rica, Jamaica, Mexico, Panama, Puerto Rico, Venezuela. 
13. Badhamia utricularis (Bull.) Berk., 1852

Recorded in 4. On BW. In LRF. Vouchers in M. Distribution: Costa Rica, Mexico.

14. Barbeyella minutissima Meyl., 1914

Recorded in 1. On BW. In SRP. Vouchers in CR. Distribution: Costa Rica, Mexico.

15. Calonema aureum Morgan, 1893

Recorded in 4. On BW, In TWF. Vouchers in UARKM. Not known from other areas in

Mesoamerica and the Caribbean. Reported from Costa Rica by Walker et al. (2015b).

16. Ceratiomyxa fruticulosa (O.F. Müll.) T. Macbr., 1899

Recorded in all provinces. On BW, GL, FR, LI, LC, TW. In TDF, TMF, PMF, LMF, TWF,

PWF, LWF, PRF, LRF, MRF. Vouchers in M, UARKM, CR, USJ. Distribution: Colombia,

Costa Rica, Cuba, Dominican Republic, El Salvador, Guatemala, Haiti, Honduras, Jamaica,

Leeward Islands, Mexico, Nicaragua, Panama, Puerto Rico, Trinidad and Tobago, Venezuela,

Windward Islands.

17. Ceratiomyxa morchella A.L. Welden, 1954

Recorded in 3, 5, 6 and 7. On BW, GL. In TDF, TWF, PRF. Vouchers in M, CR, USJ.

Distribution: Costa Rica, Honduras, Jamaica, Mexico, Panama, Puerto Rico, Trinidad and

Tobago, Venezuela, Windward Islands.

18. Ceratiomyxa sphaerosperma Boedijn, 1927

Recorded in 3 and 7. On GL. In TWF. Vouchers in M, USJ, INII. Distribution: Colombia,

Costa Rica, Cuba, Jamaica, Mexico, Panama, Puerto Rico, Venezuela, Windward Islands.

19. Clastoderma debaryanum A. Blytt, 1880

Recorded in all provinces except for 4. On BW, GL, AL, TW. In TDF, TMF, PMF, TWF,

PWF, PRF, MRF, SRP. Vouchers in M, UARKM, CR, USJ, INII. Distribution: Colombia,

Costa Rica, Cuba, El Salvador, Honduras, Jamaica, Leeward Islands, Mexico, Panama,

Puerto Rico, Trinidad and Tobago, Venezuela, Windward Islands.

20. Clastoderma pachypus Nann.-Bremek., 1968

Recorded in 5 and 6. On BW, AL. In TDF, PRF. Vouchers in M, CR. Distribution: Costa

Rica, Mexico.

21. Collaria arcyrionema (Rostaf.) Nann.-Bremek. ex Lado, 1991

Recorded in 1, 3, 5, 6 and 7. On BW, GL, AL, FI, LI, LP, TW. In TDF, TMF, PMF, LMF,

TWF, PWF, LWF, PRF, LRF. Vouchers in M, UARKM, CR, USJ, INII. Distribution: Belize,

Costa Rica, Cuba, Dominican Republic, El Salvador, Haiti, Honduras, Jamaica, Leeward

Islands, Mexico, Nicaragua, Panama, Puerto Rico, Windward Islands.

22. Collaria lurida (Lister) Nann.-Bremek., 1975

Recorded in 3, 5, 6 and 7. On BW, GL, AL. In TDF, TMF, TWF, PWF, PRF. Vouchers in M,

UARKM, CR, USJ, INII. Distribution: Colombia, Costa Rica, Cuba, Mexico, Panama, Puerto

Rico.

23. Collaria rubens (Lister) Nann.-Bremek., 1975

Recorded in 6 and 7. On GL. In TMF, PRF. Vouchers in UARKM. Distribution: Costa Rica, Mexico.

24. Colloderma oculatum (C. Lippert) G. Lister, 1910

Recorded in 1. On BW. In LWF. Vouchers in INII. Not known from other areas in

Mesoamerica and the Caribbean. Reported from Costa Rica by Rojas et al. (2015b).

25. Comatricha alta Preuss, 1851

Recorded in 4. On BW. In TWF. Vouchers in UARKM. Not known from other areas in

Mesoamerica and the Caribbean. Reported from Costa Rica by Walker et al. (2015b).

26. Comatricha elegans (Racib.) G. Lister, 1909

Recorded in 4 and 5. On BW, GL, AL, TW. In LWF, PRF. Vouchers in CR, INII.

Distribution: Colombia, Costa Rica, Cuba, Haiti, Jamaica, Mexico, Puerto Rico, Trinidad and

Tobago, Venezuela, Windward Islands.

27. Comatricha laxa Rostaf., 1874 
Recorded in 3, 5 and 6. On BW, GL, AL. In TMF, TWF, PWF, PRF. Vouchers in UARKM, CR, USJ, INII. Distribution: Colombia, Costa Rica, Cuba, El Salvador, Guatemala, Leeward Islands, Mexico, Panama, Puerto Rico, Venezuela.

28. Comatricha laxifila R.K. Chopra \& T.N. Lakh., 1992

Recorded in 6. On BW. In TDF. Vouchers in M. Not known from other areas in Mesoamerica and the Caribbean. Reported from Costa Rica by Rojas et al. (2010a).

29. Comatricha nigra (Pers. ex J.F. Gmel.) J. Schröt., 1885

Recorded in all provinces. On BW, AL, GL, FI, TW. In TDF, TMF, PMF, TWF, PWF, LWF,

PRF, LRF, MRF, SRP. Vouchers in M, UARKM, CR, USJ, INII. Distribution: Costa Rica, Cuba, El Salvador, Guatemala, Honduras, Jamaica, Leeward Islands, Mexico, Panama.

30. Comatricha pulchella (C. Bab.) Rostaf., 1876

Recorded in all provinces except for 2. On BW, GL, AL, LC, TW. In TDF, TMF, TWF, PWF, LWF, PRF, MRF, SRP. Vouchers in M, UARKM, CR, USJ, INII. Distribution: Colombia, Costa Rica, El Salvador, Honduras, Jamaica, Leeward Islands, Mexico, Panama, Puerto Rico, Venezuela.

31. Comatricha tenerrima (M.A. Curtis) G. Lister, 1919

Recorded in all provinces. On BW, GL, AL, FI, LC, TW. In TDF, TMF, PMF, TWF, PWF, LWF, PRF, MRF, SRP. Vouchers in M, UARKM, CR, USJ, INII. Distribution: Colombia, Costa Rica, Cuba, El Salvador, Honduras, Jamaica, Leeward Islands, Mexico, Panama, Puerto Rico, Venezuela.

32. Cornuvia serpula (Wigand) Rostaf., 1873

Recorded in 6. On GL. In LWF. Vouchers in INII. Distribution: Costa Rica, Mexico.

33. Craterium aureum (Schumach.) Rostaf., 1874

Recorded in 3, 5 and 6. On GL, AL. In TDF, TWF, PRF. Vouchers in UARKM, CR, USJ. Distribution: Colombia, Costa Rica, Dominican Republic, Jamaica, Mexico, Panama, Puerto Rico, Venezuela, Windward Islands.

34. Craterium concinnum Rex, 1893

Recorded in 1 and 5. On BW, GL, AL, FI. In PWF, LWF, MRF, SRP. Vouchers in M, CR, USJ. Distribution: Colombia, Costa Rica, Cuba, Jamaica, El Salvador.

35. Craterium leucocephalum (Pers. ex J.F. Gmel.) Ditmar, 1813

Recorded in all provinces except for 4. On GL, AL. In TDF, TMF, PMF, TWF, PWF, PRF,

LRF. Vouchers in M, UARKM, CR, USJ. Distribution: Colombia, Costa Rica, Cuba, El

Salvador, Guatemala, Jamaica, Leeward Islands, Mexico, Panama, Puerto Rico, Trinidad and

Tobago, Venezuela, Windward Islands.

36. Craterium minutum (Leers) Fr., 1829

Recorded in 1. On GL. In LMF, MWF. Vouchers in USJ. Distribution: Colombia, Costa Rica,

Cuba, Mexico.

37. Craterium muscorum Ing, 1982

Recorded in 1. On BW. In LWF. Vouchers in MA. Not known from other areas in

Mesoamerica and the Caribbean. Reported from Costa Rica by Lado et al. (2018).

38. Craterium paraguayense (Speg.) G. Lister, 1911

Recorded in 1 and 5. On GL, LP. In PWF. Vouchers in M, USJ. Distribution: Colombia,

Costa Rica, Cuba, Mexico, Panama, Puerto Rico, Venezuela.

39. Cribraria aurantiaca Schrad., 1797

Recorded in 4. On GL. In LRF. Vouchers in M. Distribution: Costa Rica, Jamaica, Mexico,

Panama, Venezuela.

40. Cribraria cancellata (Batsch) Nann.-Bremek., 1975

Recorded in 1, 3, 4, 6 and 7. On BW, GL. In TDF, PMF, TWF, PRF. Vouchers in M, UARKM, CR, USJ, INII. Distribution: Bahamas, Belize, Colombia, Costa Rica, Cuba, Guatemala, Honduras, Jamaica, Leeward Islands, Mexico, Nicaragua, Panama, Puerto Rico, Trinidad and Tobago, Venezuela, Windward Islands.

41. Cribraria confusa Nann.-Bremek. \& Y. Yamam., 1893 
Recorded in 6. On BW. In TDF. Vouchers in M. Distribution: Costa Rica, Cuba, Mexico, Windward Islands.

42. Cribraria costata Dhillon \& Nann.-Bremek., 1978

Recorded in 4. On BW, GL, DU. In LRF. Vouchers in M. Not known from other areas in Mesoamerica and the Caribbean. Reported from Costa Rica by Rojas et al. (2010a).

43. Cribraria intricata Schrad., 1797

Recorded in 1, 3, 4, 5 and 6. On BW, GL. In TDF, TMF, PMF, TWF, PWF, PRF, LRF, MRF. Vouchers in M, CR, USJ, INII. Distribution: Colombia, Costa Rica, Cuba, Jamaica, Leeward Islands, Mexico, Panama, Puerto Rico, Trinidad and Tobago, Venezuela, Windward Islands.

44. Cribraria languescens Rex, 1891

Recorded in 1, 3, 6 and 7. On BW, GL. In TDF, TMF, PMF, LMF. Vouchers in M, UARKM,

USJ. Distribution: Costa Rica, Guatemala, Honduras, Jamaica, Leeward Islands, Mexico,

Panama, Puerto Rico, Trinidad and Tobago, Venezuela, Windward Islands.

45. Cribraria macrocarpa Schrad., 1797

Recorded in 4. On BW. In LRF. Vouchers in M. Distribution: Colombia, Costa Rica, Cuba, Mexico.

46. Cribraria microcarpa (Schrad.) Pers., 1801

Recorded in 2, 3, 5, 6 and 7. On BW, GL, AL, TW. In TDF, TMF, PMF, TWF, PWF, LWF, PRF. Vouchers in M, UARKM, CR, USJ, INII. Distribution: Belize, Colombia, Costa Rica, Cuba, El Salvador, Honduras, Jamaica, Leeward Islands, Mexico, Panama, Puerto Rico, Trinidad and Tobago, Venezuela, Windward Islands.

47. Cribraria mirabilis (Rostaf.) Massee, 1892

Recorded in 1. On BW, TW. In MRF, SRP. Vouchers in CR, USJ. Distribution: Costa Rica, Mexico.

48. Cribraria oregana H.C. Gilbert, 1932

Recorded in 5. On BW. In TDF. Vouchers in M. Distribution: Costa Rica, Guatemala, Mexico. Reported from Costa Rica by Schnittler \& Stephenson (2000) as Cribraria vulgaris var. oregana.

49. Cribraria piriformis Schrad., 1797

Recorded in 1. On BW. In MRF, SRP. Vouchers in CR. Distribution: Costa Rica, Guatemala, Mexico, Panama.

50. Cribraria purpurea Schrad., 1797

Recorded in 1 and 5. On BW. In PWF, MRF. Vouchers in M, USJ. Distribution: Costa Rica, Mexico, Venezuela.

51. Cribraria splendens (Schrad.) Pers., 1801

Recorded in 1 and 3. On BW. In PMF, LMF, TWF, LRF. Vouchers in USJ. Distribution:

Costa Rica, Jamaica, Leeward Islands, Mexico, Venezuela.

52. Cribraria tenella Schrad., 1797

Recorded in all provinces except 7. On BW, GL. In TDF, TMF, PMF, TWF, PWF, LWF, PRF. Vouchers in M, CR, USJ, INII. Distribution: Colombia, Costa Rica, Cuba, Dominican Republic, El Salvador, Haiti, Honduras, Jamaica, Leeward Islands, Mexico, Panama, Puerto

Rico, Venezuela, Windward Islands.

53. Cribraria violacea Rex, 1891

Recorded in 1, 3, 5, 6 and 7. On BW, GL, AL, LC, TW. In TDF, TMF, PMF, TWF, PWF, LWF, PRF. Vouchers in M, UARKM, CR, USJ, INII. Distribution: Costa Rica, Cuba, El Salvador, Honduras, Jamaica, Leeward Islands, Mexico, Panama, Puerto Rico, Trinidad and Tobago, Venezuela, Windward Islands.

54. Cribraria vulgaris Schrad., 1797

Recorded in 1, 4, 5 and 6. On BW, GL, LC, TW. In PWF, PRF, LRF, MRF, SRP. Vouchers in M, UARK, CR, USJ. Distribution: Costa Rica, Guatemala, Mexico.

55. Diachea bulbillosa (Berk. \& Broome) Lister, 1898 
Recorded in 5 and 6. On BW, GL, LP. In TDF, TMF, PWF. Vouchers in M, USJ, INII. Distribution: Colombia, Costa Rica, Cuba, El Salvador, Honduras, Jamaica, Mexico, Panama, Puerto Rico, Venezuela, Windward Islands.

56. Diachea leucopodia (Bull.) Rostaf., 1874

Recorded in all provinces except 2. On BW, GL, TW. In TDF, TMF, PMF, LMF, TWF, PWF, LWF, PRF, LRF. Vouchers in F, M, UARKM, CR, USJ, INII. Distribution: Colombia, Costa Rica, Cuba, Dominican Republic, El Salvador, Guatemala, Honduras, Jamaica, Leeward Islands, Mexico, Panama, Puerto Rico, Trinidad and Tobago, Venezuela, Windward Islands.

57. Dictydiaethalium plumbeum (Schumach.) Rostaf., 1894

Recorded in 3 and 4. On LP. In LMF, MRF. Vouchers in USJ. Distribution: Colombia, Costa

Rica, Cuba, Dominican Republic, Leeward Islands, Mexico, Nicaragua, Panama, Puerto

Rico, Venezuela.

58. Dictydiaethalium dictyosporum Nann.-Bremek., 1966

Recorded in 2. On BW. In TWF. Vouchers in MA. Not known from other areas in

Mesoamerica and the Caribbean. Reported from Costa Rica by Lado et al. (2018).

59. Diderma chondrioderma (de Bary \& Rostaf.) Kuntze, 1898

Recorded in 5. On BW, GL, LC. In PWF, MRF. Vouchers in UARKM, CR, USJ.

Distribution: Belize, Costa Rica, Jamaica, Mexico, Panama, Puerto Rico, Windward Islands.

60. Diderma corrugatum T.E. Brooks \& H.W. Keller, 1977

Recorded in 6. On BW, LI. In TDF. Vouchers in M. Distribution: Costa Rica, Cuba.

61. Diderma deplanatum Fr., 1829

Recorded in 6. On BW, GL. In TDF, LWF, PRF. Vouchers in M. Distribution: Costa Rica, Mexico.

62. Diderma effusum (Schwein.) Morgan, 1894

Recorded in all provinces except 2. On BW, GL, AL, FI, LI, LC. In TDF, TMF, PMF, TWF, PWF, LWF, PRF, LRF. Vouchers in M, UARKM, CR, USJ, INII. Distribution: Belize, Colombia, Costa Rica, Cuba, El Salvador, Honduras, Jamaica, Leeward Islands, Mexico, Panama, Puerto Rico, Trinidad and Tobago, Venezuela, Windward Islands.

63. Diderma globosum Pers., 1794

Recorded in 5. On BW. In PWF. Vouchers in M. Distribution: Costa Rica, Venezuela.

64. Diderma hemisphaericum (Bull.) Hornem., 1829

Recorded in all provinces. On BW, GL, AL, FI, LI, LC. In TDF, TMF, PMF, LMF, TWF, PWF, LWF, PRF, MRF, SRP. Vouchers in M, UARKM, CR, USJ, INII. Distribution: Colombia, Costa Rica, Cuba, El Salvador, Guatemala, Haiti, Honduras, Jamaica, Leeward Islands, Mexico, Panama, Puerto Rico, Trinidad and Tobago, Venezuela, Windward Islands.

65. Diderma indicum K.S. Thind \& H.S. Sehgal, 1964

Recorded in 1. On LP. In PMF. Vouchers in USJ. Not known from other areas in

Mesoamerica and the Caribbean. Reported by Rojas et al. (2010a)

66. Diderma montanum (Meyl.) Meyl., 1913

Recorded in 1. On GL. In MRF. Vouchers in M. Distribution: Costa Rica, Venezuela.

67. Diderma ochraceum Hoffm., 1796

Recorded in 1. On LC. In MRF. Vouchers in UARKM. Distribution: Colombia, Costa Rica.

68. Diderma rimosum Eliasson \& Nann.-Bremek., 1983

Recorded in 4. On BW, GL. In TWF. Vouchers in UARKM and INII. Distribution: Costa

Rica, Mexico. Reported from Costa Rica by Walker et al. (2015b).

69. Diderma rugosum (Rex) T. Macbr., 1899

Recorded in 6 and 7. On GL. In TMF, PRF. Vouchers in M. Distribution: Costa Rica, El

Salvador, Jamaica, Leeward Islands, Mexico, Panama, Trinidad and Tobago, Windward Islands.

70. Diderma saundersii (Berk. \& Broome ex Massee) E. Sheld., 1895

Recorded in 3. On GL. In TWF. Vouchers in M. Distribution: Costa Rica, Mexico. 
71. Diderma sauteri (Rostaf.) E. Sheld., 1895

Recorded in 1. On GL. In PMF, PWF. Vouchers in CR, USJ. Distribution: Costa Rica, Mexico, Venezuela.

72. Diderma spumarioides (Fr. \& Palmquist ) Fr., 1829

Recorded in 5. On GL, LP. In TWF. Vouchers in M, USJ and INII. Distribution: Costa Rica, Cuba, Guatemala, Jamaica, Leeward Islands, Mexico, Panama, Puerto Rico, Venezuela, Windward Islands.

73. Diderma subdictyospermum (Rostaf.) E. Sheld., 1895

Recorded in 5. On GL. In PWF. Vouchers in M, UARKM. Distribution: Costa Rica, Mexico, Venezuela.

74. Diderma subincarnatum Kowalski, 1967

Cited by Rojas et al. (2010a). The specimen corresponds with collection BPI 815232 (US

National Fungus Collection) collected by CJ Alexopoulos and JA Sáenz on October 16, 1964 and identified by GW Martin. Record information also on GBIF (https://www.gbif.org/occurrence/78586863). Distribution: Costa Rica, Mexico.

75. Diderma testaceum (Schrad.) Pers., 1801

Recorded in 1, 5 and 6. On GL, AL, FI. In TMF, TWF, PWF, PRF, MRF. Vouchers in M, UARKM, CR, USJ. Distribution: Costa Rica, Cuba, Dominican Republic, Jamaica, Leeward Islands, Mexico.

76. Didymium anellus Morgan, 1894

Recorded in 3, 4, 5 and 6. On GL, AL. In TDF, TMF, TWF, PWF, PRF. Vouchers in M, UARKM, INII. Distribution: Colombia, Costa Rica, Guatemala, Jamaica, Mexico, Panama, Puerto Rico, Trinidad and Tobago.

77. Didymium bahiense Gottsb., 1968

Recorded in all provinces except 7. On GL, AL, FI. In TDF, TMF, PMF, LMF, TWF, PWF, LWF, PRF, MRF, SRP. Vouchers in M, UARKM, CR, USJ, INII. Distribution: Colombia, Costa Rica, Cuba, El Salvador, Guatemala, Honduras, Mexico, Panama, Venezuela.

78. Didymium clavus (Alb. \& Schwein.) Rabenh., 1844

Recorded in all provinces except 2. On BW, GL, AL, FI. In TDF, TMF, PMF, LMF, TWF, PWF, LWF, PRF, LRF, MRF, SRP. Vouchers in M, UARKM, CR, USJ, INII. Distribution: Belize, Colombia, Costa Rica, Cuba, El Salvador, Guatemala, Haiti, Honduras, Jamaica, Leeward Islands, Mexico, Puerto Rico, Trinidad and Tobago, Venezuela, Windward Islands.

79. Didymium comatum (Lister) Nann.-Bremek., 1966

Recorded in 5. On GL. In PWF. Vouchers in M. Distribution: Costa Rica, Windward Islands.

80. Didymium crustaceum Fr., 1829

Recorded in 1 and 4. On BW. In MRF. Vouchers in USJ. Distribution: Costa Rica, Cuba, Mexico, Windward Islands.

81. Didymium difforme (Pers.) Gray, 1821

Recorded in all provinces. On BW, GL, AL, FI. In TMF, PMF, LMF, TWF, PWF, LWF, PRF, LRF, MRF, SRP. Vouchers in M, UARKM, CR, USJ, INII. Distribution: Colombia, Costa Rica, Cuba, El Salvador, Guatemala, Haiti, Honduras, Jamaica, Mexico, Panama, Venezuela, Windward Islands.

82. Didymium dubium Rostaf., 1874

Recorded in all provinces except 2. On BW, GL, FR, DU. In TDF, TMF, PMF, TWF, PWF, LWF. Vouchers in M, USJ, INII. Distribution: Colombia, Costa Rica, El Salvador, Guatemala, Honduras, Mexico, Venezuela.

83. Didymium floccosum G.W. Martin, K.S. Thind \& Rehill, 1959

Recorded in 6. On GL. In TDF. Vouchers in M. Distribution: Costa Rica, Mexico, Venezuela. 84. Didymium iridis (Ditmar) Fr., 1829

Recorded in all provinces. On BW, GL, AL, FI, FR, LC. In TDF, TMF, PMF, LMF, TWF, PWF, LWF, PRF, LRF, MRF, SRP. Vouchers in M, UARKM, CR, USJ, INII. Distribution: Colombia, Costa Rica, Cuba, Dominica, El Salvador, Guatemala, Haiti, Honduras, Jamaica, 
Leeward Islands, Mexico, Nicaragua, Panama, Puerto Rico, Trinidad and Tobago, Venezuela, Windward Islands

85. Didymium laxifilum G. Lister \& J. Ross, 1945

Recorded in 1. On GL. In PMF. Vouchers in USJ. Distribution: Costa Rica, Mexico.

86. Didymium listeri Massee, 1892

Recorded in 5. On GL. In PWF. Vouchers in M. Distribution: Costa Rica, Mexico.

87. Didymium megalosporum Berk. \& M.A. Curtis, 1873

Cited by Clark (2004). The species was identified with material isolated in laboratory conditions and identified by J Clark. Distribution: Costa Rica, Mexico, Venezuela.

88. Didymium melanospermum (Pers.) T. Macbr., 1899

Recorded in 1. On GL. In SRP. Vouchers in CR, USJ. Distribution: Costa Rica, Cuba,

Dominican Republic, Honduras, Jamaica, Leeward Islands, Mexico, Venezuela, Windward Islands. Reported in Rojas et al. (2015b).

89. Didymium minus (Lister) Morgan, 1894

Recorded in all provinces. On BW, GL, AL, LC. In TDF, TMF, PMF, LMF, TWF, PWF, LWF, PRF, MRF, SRP. Vouchers in M, UARKM, CR, USJ, INII. Distribution: Colombia, Costa Rica, El Salvador, Guatemala, Honduras, Jamaica, Leeward Islands, Mexico, Windward Islands.

90. Didymium nigripes (Link) Fr., 1829

Recorded in al provinces. On BW, GL, AL, FI, LP. In TDF, TMF, PMF, LMF, TWF, PWF, LWF, PRF, LRF, MRF, SRP. Vouchers in M, UARKM, CR, USJ, INII. Distribution: Colombia, Costa Rica, Cuba, Dominican Republic, El Salvador, Guatemala, Haiti, Honduras, Jamaica Leeward Islands, Mexico, Panama, Puerto Rico, Trinidad and Tobago, Venezuela, Windward Islands.

91. Didymium ochroideum G. Lister, 1931

Recorded in 1, 4, 5, 6 and 7. On BW, GL, AL, FR. In TDF, TMF, PMF, TWF, PWF, PRF.

Vouchers in M, UARKM, CR. Distribution: Costa Rica, Mexico, Panama, Puerto Rico.

92. Didymium ovoideum Nann.-Bremek., 1958

Recorded in 4. On GL. In LMF. Vouchers in CR. Distribution: Costa Rica, Mexico.

93. Didymium serpula Fr., 1829

Recorded in 2 and 6. On GL, LP. In LWF, TWF. Vouchers in M, INII. Distribution: Belize,

Costa Rica, Mexico. Reported in Rojas et al. (2015b).

94. Didymium squamulosum (Alb. \& Schwein.) Fr. \& Palmquist, 1818

Recorded in all provinces. On BW, GL, AL, FI, LC, LP, DU. In TDF, TMF, PMF, LMF, TWF, PWF, LWF, PRF, LRF, MRF, SRP. Vouchers in F, M, UARKM, CR, USJ, INII. Distribution: Bahamas, Colombia, Costa Rica, Cuba, Dominican Republic, El Salvador, Guatemala, Haiti, Honduras, Jamaica Leeward Islands, Mexico, Nicaragua, Panama, Puerto Rico, Trinidad and Tobago, Venezuela, Windward Islands.

95. Didymium sturgisii Hagelst., 1937

Cited by Rojas et al. (2010a). The specimens correspond with collections 13725 and 13726 from Martin Schnittler. Distribution: Costa Rica, Mexico.

96. Echinostelium apitectum K.D. Whitney, 1980

Recorded in 6. On BW. In TDF. Vouchers in UARKM. Distribution: Costa Rica, Mexico.

97. Echinostelium bisporum (L.S. Olive \& Stoian.) K.D. Whitney \& L.S. Olive, 1982

Cited by Moore \& Stephenson (2003). Voucher information of this collection could not be retrieved. Information was recorded during research. Distribution: Costa Rica, Cuba.

98. Echinostelium minutum de Bary, 1829

Recorded in 3, 5 and 6. On BW, AL. In TDF, TMF, TWF, PWF, PRF. Vouchers in M, UARKM, CR. Distribution: Colombia, Costa Rica, Cuba, El Salvador, Guatemala, Jamaica, Leeward Islands, Mexico, Panama, Puerto Rico, Trinidad and Tobago, Windward Islands.

99. Enerthenema papillatum (Pers.) Rostaf., 1876

Recorded in 1. On TW. In MRF. Vouchers in CR. Distribution: Costa Rica, Mexico, Panama. 
100. Fuligo cinerea (Schwein.) Morgan, 1896

Cited by Schnittler \& Stephenson (2000). There is no voucher of this collection deposited anywhere but information was recorded during research. Distribution: Costa Rica, Cuba, Jamaica, Leeward Islands, Mexico, Windward Islands

101. Fuligo intermedia T. Macbr., 1922

Cited by Rojas et al. (2010a). The specimen corresponds with collection BPI 746184 (US National Fungus Collection) collected by CJ Alexopoulos and JA Sáenz in 1963 and identified by the former. Distribution: Costa Rica, Mexico.

102. Fuligo megaspora Sturgis, 1913

Recorded in 3 and 4. On LP. In LMF, PWF. Vouchers in USJ. Distribution: Costa Rica, Guatemala, Mexico.

103. Fuligo septica (L.) F.H. Wigg., 1780

Recorded in all provinces. On BW, GL. In TDF, TMF, PMF, LMF, TWF, PWF, LWF, LRF. Vouchers in F, M, CR, USJ. Distribution: Costa Rica, Cuba, Dominican Republic, El Salvador, Guatemala, Jamaica Leeward Islands, Mexico, Nicaragua, Panama, Puerto Rico, Trinidad and Tobago, Venezuela, Windward Islands.

104. Hemitrichia calyculata (Speg.) M.L. Farr, 1974

Recorded in all provinces. On BW, GL, FI, LI, LP, TW. In TDF, TMF, PMF, TWF, PWF, LWF, MWF, PRF, LRF, MRF, SRP Vouchers in F, M, CR, UARKM, USJ, INII. Distribution: Colombia, Costa Rica, Cuba, Dominican Republic, El Salvador, Guatemala, Honduras, Jamaica Leeward Islands, Mexico, Nicaragua, Panama, Puerto Rico, Trinidad and Tobago, Venezuela, Windward Islands.

105. Hemitrichia clavata (Pers.) Rostaf, 1873

Recorded in 4. On BW. In TWF. Vouchers deposited in F (FH 00276789 by CW Dodge). Distribution: Bahamas, Colombia, Costa Rica, Cuba, Dominican Republic, Jamaica Leeward Islands, Mexico, Puerto Rico, Trinidad and Tobago, Venezuela, Windward Islands.

106. Hemitrichia leiocarpa (Cooke) Lister, 1894

Recorded in 1 and 5. On BW, GL, TW. In TWF, MRF. Vouchers in M, UARJ. Distribution:

Belize, Colombia, Costa Rica, Cuba, Mexico, Panama, Windward Islands.

107. Hemitrichia minor G. Lister, 1911

Recorded in all provinces except 2. On BW, GL, AL. In TDF, TMF, PMF, LMF, TWF, PWF, LWF, PRF. Vouchers in M, UARKM, CR, INII. Distribution: Belize, Costa Rica, Mexico, Panama, Windward Islands.

108. Hemitrichia pardina (Minakata) Ing, 1999

Recorded in 1, 3, 4 and 5. On BW, GL, AL, LI, LC. In TMF, PMF, TWF, PWF, PRF. Vouchers in UARKM, CR, INII. Distribution: Colombia, Costa Rica, Cuba, El Salvador, Honduras, Mexico, Panama, Puerto Rico.

109. Hemitrichia serpula (Scop.) Rostaf. ex Lister, 1894

Recorded in all provinces. On BW, GL, AL, LI, LP, TW. In TDF, TMF, PMF, TWF, PWF, LWF, PRF, LRF, MRF. Vouchers in M, CR, UARKM, USJ, INII. Distribution: Colombia, Costa Rica, Cuba, Dominican Republic, El Salvador, Guatemala, Jamaica, Leeward Islands, Mexico, Nicaragua, Panama, Puerto Rico, Trinidad and Tobago, Venezuela, Windward Islands.

110. Lamproderma arcyrioides (Sommerf.) Rostaf., 1874

Recorded in 4 and 5. On GL. In PRF, LRF. Vouchers in M, CR. Distribution: Costa Rica, Dominican Republic, El Salvador, Jamaica, Mexico, Puerto Rico.

111. Lamproderma columbinum (Pers.) Rostaf., 1873

Recorded in 1. On BW, LC. In MRF. Vouchers in UARKM, CR, USJ. Distribution: Costa Rica, Mexico.

112. Lamproderma echinulatum (Berk.) Rostaf., 1876

Recorded in 1. On BW, LC. In MRF. Vouchers in USJ. Distribution: Costa Rica, Mexico.

113. Lamproderma magniretisporum G. Moreno, C. Rojas, S.L. Stephenson \& H. Singer, 2009 
Recorded in 1. On BW. In SRP. Vouchers in UARKM. Not known from other areas in Mesoamerica and the Caribbean. Reported from Costa Rica by Moreno et al (2009) and Rojas et al. (2010a).

114. Lamproderma muscorum (Lév.) Hagelst., 1935

Recorded in 5. On BW. In PWF. Vouchers in M. Distribution: Colombia, Costa Rica, El Salvador, Mexico, Venezuela.

115. Lamproderma sauteri Rostaf., 1874

Recorded in 1. On BW. In MRF. Vouchers in CR. Not known from other areas in Mesoamerica and the Caribbean. Reported from Costa Rica by Rojas \& Stephenson (2007) and Rojas et al. (2010a)

116. Lamproderma scintillans (Berk. \& Broome) Morgan, 1894

Recorded in al provinces. On BW, GL, AL, FI, LC, TW. In TDF, TMF, PMF, LMF, TWF, PWF, LWF, MWF, PRF, LRF, MRF. Vouchers in M, CR, UARKM, USJ, INII. Distribution: Colombia, Costa Rica, Cuba, El Salvador, Guatemala, Haiti, Honduras, Jamaica Leeward Islands, Mexico, Panama, Puerto Rico, Venezuela, Windward Islands.

117. Leocarpus fragilis (Dicks.) Rostaf., 1874

Recorded in 1. On BW, GL, TW. In LRF, MRF, SRP. Vouchers in M, UARKM, USJ. Distribution: Colombia, Costa Rica, Mexico.

118. Lepidoderma trevelyanii (Grev.) Poulain \& Mar. Mey., 2002

Recorded in 5. On BW. In PWF. Vouchers in M. Not known from other areas in

Mesoamerica and the Caribbean. Reported from Costa Rica by Rojas et al. (2010a).

119. Licea belmontiana Nann.-Bremek., 1966

Recorded in 1. On TW. In MRF. Vouchers in CR. Distribution: Costa Rica, Guatemala, Mexico, Panama. Reported from Costa Rica by Rojas et al. (2017).

120. Licea biforis Morgan, 1893

Recorded in 3. On AL. In TWF. Vouchers in UARKM. Distribution: Belize, Colombia, Costa Rica, Cuba, Jamaica, Mexico, Panama.

121. Licea castanea G. Lister, 1911

Recorded in 6. On GL. In LWF. Vouchers in USJ, INII. Distribution: Costa Rica, Mexico.

Reported from Costa Rica by Rojas et al. (2015b).

122. Licea denudescens H.W. Keller \& T.E. Brooks, 1977

Recorded in 7. On BW. In TMF. Vouchers in M. Distribution: Belize, Costa Rica, Mexico.

123. Licea erecta K.S. Thind \& Dhillon, 1967

Recorded in 5. On GL. In PWF. Vouchers in M. Distribution: Belize, Costa Rica, Cuba.

124. Licea minima Fr., 1829

Recorded in 1, 2, 5 and 7. On BW, GL, AL, FI, TW. In LWF, MRF, SRP. Vouchers in M, UARK, CR, USJ. Distribution: Colombia, Costa Rica, Guatemala, Mexico, Panama.

125. Licea operculata (Wingate) G.W. Martin, 1942

Recorded in 3, 4, 6 and 7. On BW, AL. In TDF, TMF, PMF, TWF. Vouchers in M, UARKM,

CR. Distribution: Costa Rica, Mexico, Panama, Puerto Rico, Venezuela, Windward Islands.

126. Licea pedicellata (H.C. Gilbert) H.C. Gilbert, 1942

Recorded in 6. On BW. In TDF. Vouchers in M. Distribution: Costa Rica, Cuba, Mexico, Panama, Puerto Rico, Windward Islands.

127. Licea perexigua T.E. Brooks \& H.W. Keller, 1977

Recorded in 6. On GL. In TDF. Vouchers in M. Distribution: Belize, Costa Rica, Mexico.

128. Licea pusilla Schrad., 1797

Recorded in 2 and 5. On BW. In TMF, PWF. Vouchers in USJ, INII. Distribution: Colombia,

Costa Rica, El Salvador, Guatemala, Jamaica, Mexico, Panama.

129. Licea testudinacea Nann.-Bremek., 1965

Recorded in 1 and 4. On GL. In SRP. Vouchers in UARKM. Distribution: Costa Rica, Guatemala, Mexico.

130. Lycogala conicum Pers., 1801 
Recorded in 1, 3 and 6. On BW. In TDF, PMF, TWF. Vouchers in M, CR, USJ. Distribution: Costa Rica, Cuba, Jamaica, Leeward Islands, Mexico, Nicaragua, Panama.

131. Lycogala epidendrum (L.) Fr., 1829

Recorded in all provinces except 2. On BW, GL, AL, LC. In TDF, TMF, PMF, TWF, PWF, MWF, PRF, LRF, MRF, SRP. Vouchers in M, UARKM, CR, USJ. Distribution: Bahamas, Colombia, Costa Rica, Cuba, Dominican Republic, El Salvador, Guatemala, Honduras, Jamaica, Leeward Islands, Mexico, Nicaragua, Panama, Puerto Rico, Trinidad and Tobago, Venezuela, Windward Islands.

132. Lycogala exiguum Morgan, 1893

Recorded in 1, 5 and 6. On BW, GL. In TDF, PMF, TWF, PRF. Vouchers in M, USJ. Distribution: Colombia, Costa Rica, Cuba, El Salvador, Jamaica, Leeward Islands, Mexico, Panama, Puerto Rico, Venezuela, Windward Islands.

133. Macbrideola cornea (G. Lister \& Cran) Alexop., 1967

Recorded in 6. On BW. In TDF. Vouchers in M. Distribution: Costa Rica, Cuba, Mexico.

134. Macbrideola decapillata H.C. Gilbert, 1934

Cited by Farr (1976). The specimen corresponds with slide CRmc2 made by CJ Alexopoulos and documented in Alexopoulos (1967). Distribution: Costa Rica, Mexico, Panama.

135. Macbrideola martinii (Alexop. \& Beneke) Alexop., 1967

Recorded in 5 and 6. On BW, GL, LI. In TDF, PWF. Vouchers in M, UARKM. Distribution: Belize, Costa Rica, Jamaica, Mexico, Windward Islands.

136. Macbrideola scintillans H.C. Gilbert, 1934

Recorded in 5 and 6. On BW, GL, AL. In TDF, PWF, PRF. Vouchers in M, CR. Distribution: Belize, Costa Rica, Mexico.

137. Macbrideola spinosispora L.M. Walker, G. Moreno \& S.L. Stephenson, 2014

Recorded in 4. On GL. In TWF. Vouchers in UARKM. Not known from other areas in Mesoamerica and the Caribbean. Reported from Costa Rica by Walker et al. (2014).

138. Meriderma cribrarioides (Fr.) Mar. Mey. \& Poulain, in Poulain, Meyer \& Bozonnet, 2011

Recorded in 1. On BW. In MRF. Vouchers in UARKM. Not known from other areas in Mesoamerica and the Caribbean. Reported from Costa Rica by Rojas at el. (2010a) as Lamproderma cribrarioides.

139. Metatrichia floriformis (Schwein.) Nann.-Bremek., 1985

Recorded in all provinces. On BW, GL, LI, LC, TW, DU. In TMF, PMF, LMF, TWF, PWF, PRF, LRF, MRF, SRP. Vouchers in M, UARKM, CR, USJ. Distribution: Colombia, Costa Rica, Jamaica, Mexico, Puerto Rico, Venezuela.

140. Metatrichia vesparia (Batsch) Nann.-Bremek. ex G.W. Martin \& Alexop., 1969

Recorded in 1, 3, 4, 6 and 7. On BW, GL, LP. In TDF, TMF, PMF, TWF, PWF. Vouchers in M, UARKM, CR, USJ, INII. Distribution: Costa Rica, Cuba, Dominican Republic, Jamaica, Leeward Islands, Mexico, Nicaragua, Panama, Puerto Rico, Trinidad and Tobago, Venezuela, Windward Islands.

141. Paradiacheopsis acanthodes (Alexop.) Nann.-Bremek., 1986

Recorded in 5 and 6. On GL. In TDF, LWF. Vouchers in M, INII. Not known from other areas in Mesoamerica and the Caribbean. Reported from Costa Rica by Rojas et al. (2010a).

142. Paradiacheopsis longipes Hooff \& Nann.-Bremek., 1996

Recorded in 5. On GL. In TMF, LWF. Vouchers in INII. Not known from other areas in Mesoamerica and the Caribbean. Reported from Costa Rica by Rojas et al. (2010a).

143. Paradiacheopsis rigida (Brândza) Nann.-Bremek., 1969

Recorded in 1. On GL. In SRP. Vouchers in UARKM. Distribution: Belize, Costa Rica.

144. Paradiacheopsis solitaria (Nann.-Bremek.) Nann.-Bremek., 1975

Recorded in 6. On GL. In LWF. Vouchers in INII. Distribution: Costa Rica, Mexico.

Reported from Costa Rica by Rojas et al. (2015b).

145. Perichaena chrysosperma (Curr.) Lister, 1894 
Recorded in all provinces. On BW, GL, AL, FI, TW. In TDF, TMF, PMF, LMF, TWF, PWF, LWF, PRF, LRF, MRF, SRP. Vouchers in M, UARKM, CR, USJ, INII. Distribution: Belize, Colombia, Costa Rica, Cuba, Dominican Republic, El Salvador, Guatemala, Honduras, Jamaica, Leeward Islands, Mexico, Nicaragua, Panama, Puerto Rico, Trinidad and Tobago, Venezuela, Windward Islands.

146. Perichaena corticalis (Batsch) Rostaf., 1875

Recorded in 2, 3, 4, 5 and 7. On GL, AL, FI. In TMF, PMF, LMF, TWF, PWF, LWF, SRP. Vouchers in UARKM, CR, USJ, INII. Distribution: Costa Rica, Cuba, Dominican Republic, Guatemala, Mexico, Panama.

147. Perichaena depressa Lib., 1837

Recorded in all provinces. On BW, GL, AL, FI, LP, TW. In TDF, TMF, PMF, TWF, PWF, LWF, PRF, MRF, SRP. Vouchers in M, UARKM, CR, USJ, INII. Distribution: Colombia, Costa Rica, Cuba, El Salvador, Guatemala, Honduras, Jamaica, Leeward Islands, Mexico, Nicaragua, Panama, Puerto Rico, Trinidad and Tobago, Venezuela, Windward Islands.

148. Perichaena dictyonema Rammeloo, 1981

Recorded in 3, 5 and 7. On BW, GL, FI. In TMF, TWF, PWF. Vouchers in M. Distribution: Costa Rica, Mexico, Puerto Rico.

149. Perichaena longipes L.M. Walker, Leontyev \& S.L. Stephenson, 2015

Recorded in 4. On GL. In TWF. Vouchers in UARKM. Distribution: Costa Rica, Panama. Reported from Costa Rica by Walker et al. (2015a).

150. Perichaena microspora Penz. \& Lister, 1898

Recorded in 6. On GL. In TDF. Vouchers in M. Distribution: Costa Rica, Cuba.

151. Perichaena pedata (Lister \& G. Lister) Lister ex E. Jahn, 1919

Recorded in all provinces except 2. On BW, GL. In TDF, TMF, PMF, TWF, PWF, PRF, SRP. Vouchers in M, UARKM, CR, USJ, INII. Distribution: Costa Rica, El Salvador, Honduras, Mexico, Panama.

152. Perichaena quadrata T. Macbr., 1899

Recorded in 1 and 6. On GL. In PWF, LWF. Vouchers in INII. Distribution: Costa Rica, Mexico.

153. Perichaena tessellata G. Lister, 1931

Recorded in 6. On GL. In LWF. Vouchers in INII. Distribution: Costa Rica, El Salvador. Reported from Costa Rica by Rojas et al. (2017).

154. Perichaena vermicularis (Schwein.) Rostaf., 1876

Recorded in all provinces except 2. On BW, GL, AL, FI, LP. In TDF, TMF, PMF, TWF, PWF, PRF, SRP. Vouchers in M, UARKM, CR, USJ, INII. Distribution: Costa Rica, Cuba, El Salvador, Leeward Islands, Mexico, Panama, Windward Islands.

155. Physarella oblonga (Berk. \& M.A. Curtis) Morgan, 1896

Recorded in all provinces except 2. On BW, GL, LP, TW. In TDF, TMF; PMF, TWF, PWF, LWF. Vouchers in M, UARKM, CR, USJ. Distribution: Colombia, Costa Rica, Cuba, El Salvador, Jamaica, Leeward Islands, Mexico, Nicaragua, Panama, Puerto Rico, Trinidad and Tobago, Venezuela, Windward Islands.

156. Physarina echinocephala Höhn., 1909

Recorded in 3. On AL. In PWF. Vouchers in MA. Not known from other areas in Mesoamerica and the Caribbean. Reported from Costa Rica by Lado et al. (2018).

157. Physarum aeneum (Lister) R.E. Fr., 1903

Recorded in 6. On GL. In PWF. Vouchers in INII. Distribution: Costa Rica, Leeward Islands, Mexico, Panama, Puerto Rico, Windward Islands. Reported from Costa Rica by Rojas et al. (2017).

158. Physarum album (Bull.) Chevall., 1826

Recorded in all provinces except 2. On BW; GL, AL. In TDF, TMF, PMF, LMF, TWF, PWF, LRF, MRF. Vouchers in M, UARKM, CR, USJ, INII. Distribution: Belize, Colombia, Costa 
Rica, Cuba, Dominican Republic, Guatemala, Jamaica, Mexico, Panama, Puerto Rico, Trinidad and Tobago, Venezuela, Windward Islands.

159. Physarum auriscalpium Cooke, 1877

Recorded in 3 and 5. On GL, FI. In TWF. Vouchers in M, USJ. Distribution: Belize, Costa Rica, Leeward Islands, Mexico, Panama, Puerto Rico, Venezuela, Windward Islands.

160. Physarum bitectum G. Lister, 1911

Recorded in 1 and 5. On BW, GL. In PMF; PWF; MRF. Vouchers in UARKM, USJ. Distribution: Colombia, Costa Rica, Jamaica, Mexico, Puerto Rico, Venezuela.

161. Physarum bivalve Pers., 1795

Recorded in all province except 7. On BW, GL, TW. In TDF, TMF, PMF; TWF, LRF, MRF, SRP. Vouchers in M, UARKM, CR, USJ, INII. Distribution: Colombia, Costa Rica, Cuba, El Salvador, Guatemala, Haiti, Leeward Islands, Mexico, Panama, Venezuela.

162. Physarum bogoriense Racib., 1898

Recorded in all province except for 7. On BW, GL, LP. In TDF, PMF, TWF, PWF, LWF, PRF. Vouchers in M, UARKM, CR, USJ, INII. Distribution: Colombia, Costa Rica, Cuba, Honduras, Jamaica, Leeward Islands, Mexico, Panama, Puerto Rico, Trinidad and Tobago, Venezuela, Windward Islands.

163. Physarum brunneolum (W. Phillips) Massee, 1892

Recorded in 1. On BW. In MRF. Vouchers in USJ. Distribution: Colombia, Costa Rica, Mexico.

164. Physarum cinereum (Batsch) Pers., 1794

Recorded in all provinces. On BW, GL, LP. In TDF, TMF, PMF, LMF, TWF, PWF, LWF, PRF, MRF. Vouchers in M, UARKM, CR, USJ, INII. Distribution: Colombia, Costa Rica, Cuba, Dominican Republic, El Salvador, Haiti, Honduras, Jamaica, Leeward Islands, Mexico, Nicaragua, Panama, Puerto Rico, Trinidad and Tobago, Venezuela, Windward Islands.

165. Physarum citrinum Schumach., 1803

Recorded in 1 and 2. On LC. In TMF; TWF, PWF. Vouchers in UARKM, USJ. Distribution: Colombia, Costa Rica, El Salvador, Leeward Islands, Mexico, Panama, Venezuela, Windward Islands.

166. Physarum compressum Alb. \& Schwein., 1805

Recorded in all provinces. On BW, GL, AL, FI, LC, LP, TW. In TDF, TMF, PMF, LMF, TWF, PWF, LWF, PRF, LRF, MRF, SRP. Vouchers in M, UARKM, CR, USJ, INII. Distribution: Bahamas, Belize, Colombia, Costa Rica, Cuba, Dominican Republic, El Salvador, Guatemala, Haiti, Honduras, Jamaica, Leeward Islands, Mexico, Panama, Puerto Rico, Trinidad and Tobago, Venezuela, Windward Islands.

167. Physarum contextum (Pers.) Pers., 1801

Recorded in 1. On BW. In MRF. Vouchers in USJ. Distribution: Costa Rica, Mexico, Nicaragua.

168. Physarum crateriforme Petch, 1909

Recorded in 6. On BW. In TDF. Vouchers in M. Distribution: Belize, Costa Rica, Cuba, Leeward Islands, Mexico, Panama, Puerto Rico, Windward Islands.

169. Physarum decipiens M.A. Curtis, 1848

Recorded in 3, 4, 5, 6, and 7. On BW, GL, LP. In TDF, TMF, TWF, PRF. Vouchers in M, USJ. Distribution: Costa Rica, Cuba, Mexico, Panama.

170. Physarum dictyosporum G.W. Martin, 1962

Recorded in 1 and 6. On GL. In TMF, LRF. Vouchers in USJ. Distribution: Colombia, Costa Rica, Mexico.

171. Physarum didermoides (Pers.) Rostaf., 1874

Recorded in all provinces. On BW, GL, AL, FI, LP. In TDF, TMF, PMF, LMF, TWF, PWF, LWF, PRF, LRF, SRP. Vouchers in F, M, UARKM, CR, USJ, INII. Distribution: Colombia, Costa Rica, Cuba, Dominican Republic, El Salvador, Guatemala, Jamaica, Mexico, Panama, Puerto Rico, Trinidad and Tobago, Windward Island. 
172. Physarum echinosporum Lister, 1899

Recorded in 1 and 2. On TW. In TWF, MRF. Vouchers in CR, USJ. Distribution: Colombia, Costa Rica, Guatemala, Jamaica, Leeward Islands, Mexico, Panama, Windward Islands.

173. Physarum flavicomum Berk., 1845

Recorded in 3, 4, 5 and 6. On BW, GL. In TDF, TWF, PWF, LWF, LRF. Vouchers in M, CR, USJ. Distribution: Belize, Colombia, Costa Rica, Cuba, Leeward Islands, Mexico, Trinidad and Tobago.

174. Physarum flavidum (Peck) Peck, 1878

Recorded in 2. On LP. In TMF. Vouchers in USJ. Not known from other areas in Mesoamerica and the Caribbean.

175. Physarum galbeum Wingate, 1899

Recorded in 4. On BW, GL. In PWF. Vouchers in UARKM, INII. Distribution: Colombia, Costa Rica, Cuba, Honduras, Jamaica, Mexico, Nicaragua, Panama, Windward Islands. Reported in Rojas et al. (2015b).

176. Physarum globuliferum (Bull.) Pers., 1801

Recorded in all provinces except 5. On BW, GL. In TDF, TMF, PMF, TWF, LRF. Vouchers in M, UARKM, CR, USJ. Distribution: Bahamas, Colombia, Costa Rica, Cuba, Jamaica, Leeward Islands, Mexico, Panama, Trinidad and Tobago, Venezuela.

177. Physarum gyrosum Rostaf., 1874

Recorded in 6. On LP. In TMF, PRF. Vouchers in UARKM, USJ. Distribution: Colombia, Costa Rica, Cuba, Mexico, Puerto Rico.

178. Physarum javanicum Racib., 1898

Recorded in 2, 5, 6 and 7. On BW, GL, AL, LP. In TDF, TMF, PWF, LWF, PRF. Vouchers in M, CR, USJ, INII. Distribution: Colombia, Costa Rica, Cuba, Jamaica, Mexico, Panama, Puerto Rico, Trinidad and Tobago, Venezuela.

179. Physarum lateritium (Berk. \& Ravenel) Morgan, 1896

Recorded in 3. On GL. In PWF. Vouchers in INII. Distribution: Costa Rica, Leeward Islands, Mexico, Panama, Windward Islands. Reported in Rojas et al. (2015b).

180. Physarum leucophaeum Fr. \& Palmquist, 1818

Recorded in 3 and 6. On GL. In TDF, TWF. Vouchers in CR, INII. Distribution: Costa Rica, Cuba, Dominican Republic, Jamaica, Leeward Islands, Mexico, Windward Islands.

181. Physarum leucopus Link, 1809

Recorded in 1 and 2. On BW. In TMF; LRF, MRF. Vouchers in USJ. Distribution: Colombia, Costa Rica, Cuba, Guatemala, Jamaica, Mexico, Panama, Windward Islands.

182. Physarum melleum (Berk. \& Broome) Massee, 1892

Recorded in all provinces. On BW, GL, AL, LI, LP, TW. In TDF, TMF, PMF, LMF, TWF, PWF, PRF, MRF. Vouchers in M, UARKM, CR, USJ, INII. Distribution: Colombia, Costa Rica, Cuba, Dominican Republic, Guatemala, Honduras, Jamaica, Leeward Islands, Mexico, Panama, Puerto Rico, Trinidad and Tobago, Venezuela, Windward Islands.

183. Physarum murinum Lister, 1894

Cited by Alexopoulos \& Sáenz (1975). The specimen corresponds with collection USJ151 (cited as UCR151) with original duplicate in the TEX herbarium (TEX1969). However, collections were transferred several times and the current location could not be retrieved. Distribution: Costa Rica, Mexico.

184. Physarum mutabile (Rostaf.) G. Lister, 1911

Recorded in 1 and 6. On GL. In TDF, PMF. Vouchers in USJ, INII. Distribution: Costa Rica, Cuba, Mexico, Venezuela.

185. Physarum nicaraguense T. Macbr., 1893

Recorded in 1. On LP. In PMF. Vouchers in USJ. Distribution: Belize, Costa Rica, Cuba, Haiti, Jamaica, Mexico, Nicaragua, Puerto Rico, Trinidad and Tobago. Hagelstein (1944) cited Physarum reniforme for Costa Rica. However, Farr (1976) considered it to be, in part, a synonym of $P$. nicaraguense. 
186. Physarum notabile T. Macbr., 1922

Recorded in 1, 2, 6 and 7. On BW, GL, AL, FI. In TDF, TMF, LRF. Vouchers in M, UARKM, USJ, INII. Distribution: Colombia, Costa Rica, Jamaica, Mexico, Windward Islands.

187. Physarum nucleatum Rex, 1891

Recorded in 3, 5, 6 and 7. On BW, GL, AL. In TDF, TMF, TWF, PWF, LWF, PRF. Vouchers in M, CR, USJ, INII. Distribution: Costa Rica, Cuba, Jamaica, Leeward Islands, Mexico, Nicaragua, Panama, Puerto Rico, Trinidad and Tobago, Venezuela, Windward Islands.

188. Physarum oblatum T. Macbr., 1893

Recorded in 3, 4, 5, 6 and 7. On GL, AL, FI. In TDF, TMF, PMF, TWF, PWF, PRF. Vouchers in M, UARKM, USJ, INII. Distribution: Belize, Colombia, Costa Rica, Cuba, Dominican Republic, El Salvador, Jamaica, Mexico, Panama, Venezuela, Windward Islands.

189. Physarum penetrale Rex, 1891

Recorded in 5 and 6. On BW, TW. In PWF, PRF. Vouchers in M. Distribution: Costa Rica, Jamaica, Mexico, Panama, Venezuela, Windward Islands.

190. Physarum pezizoideum (Jungh.) Pavill. \& Lagarde, 1903

Recorded in 3. On BW. In TWF. Vouchers in UARKM, CR. Distribution: Costa Rica, Cuba, Mexico.

191. Physarum polycephalum Schwein., 1822

Recorded in 1, 3, 4 and 5. On GL, TW. In TMF, PMF, LMF, TWF, PWF. Vouchers in UARKM, USJ. Distribution: Costa Rica, Cuba, Jamaica, Leeward Islands, Mexico, Nicaragua, Puerto Rico, Trinidad and Tobago, Windward Islands.

192. Physarum pulcherripes Peck, 1873

Recorded in 1, 5 and 7. On BW, GL. In TMF, TWF, PWF. Vouchers in UARKM, USJ. Distribution: Costa Rica, Jamaica, Mexico, Panama, Trinidad and Tobago, Venezuela, Windward Islands.

193. Physarum pusillum (Berk. \& M.A. Curtis) G. Lister, 1911

Recorded in all provinces. On BW, GL, AL, FI, LP, LC, TW. In TDF, TMF, PMF, LMF, TWF, PWF, LWF, PRF, LRF, MRF, SRP. Vouchers in M, UARKM, CR, USJ, INII. Distribution: Belize, Colombia, Costa Rica, Cuba, Dominican Republic, El Salvador, Guatemala, Haiti, Jamaica, Leeward Islands, Mexico, Panama, Puerto Rico, Windward Islands.

194. Physarum rigidum (G. Lister) G. Lister, 1925

Recorded in 1 and 4. On BW. In PWF, MRF. Vouchers in USJ. Distribution: Costa Rica, Cuba, Jamaica, Leeward Islands, Puerto Rico, Trinidad and Tobago.

195. Physarum robustum (Lister) Nann.-Bremek., 1973

Recorded in 1. On BW. In SRP. Vouchers in UARKM. Distribution: Costa Rica, Mexico.

196. Physarum roseum Berk. \& Broome, 1873

Recorded in 3, 5, 6 and 7. On BW, GL, AL. In TDF, TWF, PWF. Vouchers in M, UARKM, CR, USJ, INII. Distribution: Colombia, Costa Rica, Cuba, El Salvador, Jamaica, Mexico, Panama, Windward Islands.

197. Physarum serpula Morgan, 1896

Recorded in 5, 6 and 7. On BW, GL, TW. In TDF, TMF, PWF, PRF. Vouchers in M, CR. Distribution: Costa Rica, Cuba, Jamaica, Mexico, Panama, Trinidad and Tobago.

198. Physarum stellatum (Massee) G.W. Martin, 1947

Recorded in all provinces except 2. On BW, GL, TW. In TDF, TMF, TWF, PWF, LWF, PRF, LRF. Vouchers in M, UARKM, CR, USJ, INII. Distribution: Colombia, Costa Rica, Cuba, El Salvador, Jamaica, Leeward Islands, Mexico, Nicaragua, Panama, Puerto Rico, Trinidad and Tobago, Venezuela, Windward Islands.

199. Physarum straminipes Lister, 1898

Recorded in 1. On GL. In SRP. Vouchers in UARKM. Distribution: Costa Rica, Mexico. 
200. Physarum sulphureum Alb. \& Schwein., 1805

Recorded in 4. On GL. In TWF. Vouchers in UARKM. Distribution: Costa Rica, Jamaica, Leeward Islands, Mexico, Puerto Rico, Venezuela. Reported from Costa Rica by Walker et al. (2015b).

201. Physarum superbum Hagelst., 1940

Recorded in all provinces except 2. On BW, GL, AL, FI. In TDF; TMF, TWF, PWF, PRF. Vouchers in M, CR, USJ, INII. Distribution: Costa Rica, Haiti, Mexico, Panama, Puerto Rico, Venezuela.

202. Physarum tenerum Rex, 1890

Recorded in 1, 3, 5, 6 and 7. On BW, GL. In TDF, TMF, PMF, LMF, TWF, PWF, PRF, LRF. Vouchers in F, M, UARKM, CR, USJ, INII. Distribution: Colombia, Costa Rica, Honduras, Jamaica, Leeward Islands, Mexico, Nicaragua, Panama, Puerto Rico, Trinidad and Tobago, Windward Islands.

203. Physarum vernum Sommerf., 1829

Cited by Alexopoulos \& Sáenz (1975). Recorded in 2. On BW. In TWF. Distribution: Colombia, Costa Rica, Cuba, Guatemala, Mexico, Venezuela?

204. Physarum virescens Ditmar, 1817

Recorded in 4. On GL. In TDF, TWF. Vouchers in INII. Distribution: Costa Rica, Mexico, Panama, Venezuela. Reported in Rojas et al. (2017).

205. Physarum viride (Bull.) Pers., 1795

Recorded in all provinces except 7. On BW, GL. In TDF, PMF, LMF, TWF, PWF, LWF, LRF, MRF. Vouchers in M, UARKM, CR, USJ, INII. Distribution: Bahamas, Colombia, Costa Rica, Cuba, El Salvador, Honduras, Jamaica, Leeward Islands, Mexico, Nicaragua, Panama, Puerto Rico, Trinidad and Tobago, Venezuela, Windward Islands.

206. Reticularia lycoperdon Bull., 1790

Recorded in 4. On BW. In TWF. Vouchers in F. Distribution: Colombia, Costa Rica, Dominican Republic, Jamaica, Mexico, Panama, Puerto Rico, Windward Islands.

207. Reticularia splendens Morgan, 1893

Recorded in 5. On BW. In PWF. Vouchers in M. Distribution: Costa Rica, Mexico, Panama.

208. Stemonaria gracilis Nann.-Bremek. \& Y. Yamam., 1984

Recorded in 7. On BW. In TMF. Vouchers in M. Not known from other areas in

Mesoamerica and the Caribbean. Reported from Costa Rica by Rojas et al. (2010a).

209. Stemonaria longa (Peck) Nann.-Bremek., R. Sharma \& Y. Yamam., 1984

Recorded in all province except 2. On BW, LP. In TMF, PMF, TWF, PWF, LWF, PRF. Vouchers in M, UARKM, CR, USJ. Distribution: Costa Rica, Cuba, El Salvador, Jamaica, Leeward Islands, Mexico, Nicaragua, Panama, Puerto Rico, Trinidad and Tobago, Windward Islands.

210. Stemonaria rufipes Nann.-Bremek. \& Y. Yamam., 1984

Recorded in 1. On GL. In PWF. Vouchers in INII. Not known from other areas in Mesoamerica and the Caribbean. Reported from Costa Rica by Lado et al. (2018).

211. Stemonitis axifera (Bull.) T. Macbr., 1899

Recorded in 1, 3, 4, 5 and 6. On BW, GL, LC. In TDF, TMF, PMF, TWF, PWF, LWF, PRF, LRF, MRF. Vouchers in M, UARKM, CR, USJ, INII. Distribution: Colombia, Costa Rica, Cuba, Dominican Republic, El Salvador, Haiti, Honduras, Jamaica, Leeward Islands, Mexico, Nicaragua, Panama, Puerto Rico, Trinidad and Tobago, Venezuela, Windward Islands.

212. Stemonitis capillitionodosa G. Moreno, D. W. Mitch., C. Rojas \& S. L. Stephenson, 2010

This species was recorded during the spring of 1922. Vouchers are deposited in the F herbarium at Harvard University and the AH Herbarium. Reported from Costa Rica by Moreno et al. (2010). Not known from other areas in Mesoamerica and the Caribbean.

213. Stemonitis flavogenita E. Jahn, 1904 
Recorded in 1, 3, 5 and 7. On BW, AL, TW. In TWF, PRF, MRF. Vouchers in F, UARKM, CR. Distribution: Costa Rica, Cuba, Guatemala, Jamaica, Mexico, Panama, Puerto Rico, Trinidad and Tobago, Venezuela, Windward Islands.

214. Stemonitis foliicola Ing, 1967

Recorded in 3. On GL. In TWF. Vouchers in UARKM. Distribution: Costa Rica, Mexico.

215. Stemonitis fusca Roth, 1787

Recorded in all provinces. On BW, GL, AL, FI, LC, LP, TW. In TDF, TMF, PMF, LMF, TWF, PWF, LWF, MWF, PRF, LRF, MRF, SRP. Vouchers in M, UARKM, CR, USJ, INII. Distribution: Costa Rica, Cuba, Dominican Republic, El Salvador, Guatemala, Honduras, Jamaica, Leeward Islands, Mexico, Nicaragua, Panama, Puerto Rico, Venezuela, Windward Islands.

216. Stemonitis herbatica Peck, 1873

Recorded in 1 and 5. On GL. In TMF, PWF. Vouchers in UARKM, CR. Distribution: Bahamas, Belize, Colombia, Costa Rica, Cuba, Dominican Republic, Guatemala, Jamaica, Leeward Islands, Mexico, Panama, Puerto Rico, Venezuela, Windward Islands.

217. Stemonitis mussooriensis G.W. Martin, K.S. Thind \& Sohi, 1957

Recorded in 1. On GL. In SRP. Vouchers in UARKM. Distribution: Costa Rica, Mexico. Reported from Costa Rica by Rojas et al. (2017).

218. Stemonitis pallida Wingate, 1899

Recorded in 6. On BW. In PRF. Vouchers in M. Distribution: Costa Rica, Cuba, Jamaica, Mexico, Panama, Puerto Rico, Trinidad and Tobago, Venezuela.

219. Stemonitis splendens Rostaf., 1874

Recorded in 1, 3, 4, 5 and 6. On BW, GL, AL. In TDF, PMF, TWF, PWF, PRF, MRF, SRP. Vouchers in M, UARKM, CR, USJ, INII. Distribution: Belize, Colombia, Costa Rica, Cuba, Guatemala, Jamaica, Leeward Islands, Mexico, Nicaragua, Panama, Puerto Rico, Trinidad and Tobago, Venezuela, Windward Islands.

220. Stemonitopsis aequalis (Peck) Y. Yamam., 1998

Recorded in 2, 3, 4 and 6. On GL, FI. In TDF, PMF, LWF. Vouchers in USJ, INII. Distribution: Costa Rica, Honduras, Jamaica, Panama, Windward Islands.

221. Stemonitopsis amoena (Nann.-Bremek.) Nann.-Bremek., 1975

Recorded in 7. On BW, GL; FI, LP. In TMF, PMF. Vouchers in M, USJ, INII. Not know from other areas in Mesoamerica and the Caribbean. Reported from Costa Rica by Rojas et al. (2010a).

222. Stemonitopsis gracilis (G. Lister) Nann.-Bremek., 1975

Recorded in 6. On BW. In PRF. Vouchers in M. Distribution: Costa Rica, Cuba, Mexico.

223. Stemonitopsis hyperopta (Meyl.) Nann.-Bremek., 1975

Recorded in 1, 3, 4, 5 and 6. On BW, GL, TW. In TDF, TMF, TWF, PWF, PRF, LRF, MRF. Vouchers in M, CR, USJ, INII. Distribution: Costa Rica, Cuba, El Salvador, Guatemala, Jamaica, Mexico, Panama, Puerto Rico, Windward Islands.

224. Stemonitopsis subcaespitosa (Peck) Nann.-Bremek., 1975

Recorded in 3, 5 and 6. On BW, GL. In TDF, TMF, TWF, PWF, LWF, PRF. Vouchers in UARKM, USJ, INII. Distribution: Costa Rica, El Salvador, Honduras, Leeward Islands, Mexico, Windward Islands.

225. Stemonitopsis typhina (F.H. Wigg.) Nann.-Bremek., 1975

Recorded in all province except 2. On BW, GL. In TDF, TMF, PMF, TWF, PWF, LWF, PRF, LRF. Vouchers in M, UARKM, CR, USJ, INII. Distribution: Colombia, Costa Rica, Cuba, Dominican Republic, Guatemala, Jamaica, Leeward Islands, Mexico, Nicaragua, Panama, Puerto Rico, Trinidad and Tobago, Venezuela, Windward Islands.

226. Symphytocarpus herbaticus Ing, 1967

Recorded in 3, 5 and 7. On BW, GL. In TMF, TWF, PWF. Vouchers in M, UARKM, USJ. Not know from other areas in Mesoamerica and the Caribbean. Reported from Costa Rica by Rojas et al. (2010a). 
227. Trichia affinis de Bary, 1870

Recorded in 5 and 6. On BW. In TDF, PWF. Vouchers in M. Distribution: Costa Rica, Cuba, Mexico, Panama, Trinidad and Tobago.

228. Trichia botrytis (J.F. Gmel.) Pers., 1794

Recorded in 1, 3 and 4. On BW, GL, TW. In LMF, TWF, LRF, MRF. Vouchers in CR, USJ, INII. Distribution: Costa Rica, Dominican Republic, Guatemala, Jamaica, Mexico.

229. Trichia contorta (Ditmar) Rostaf., 1875

Recorded in 1 and 5. On BW. In PWF, SRP. Vouchers in M. Distribution: Costa Rica, Guatemala, Mexico.

230. Trichia decipiens (Pers.) T. Macbr., 1899

Recorded in 1, 4 and 6. On BW, GL, LC, DU. In TDF, LRF, MRF. Vouchers in M, CR, USJ, INII. Distribution: Costa Rica, Cuba, Guatemala, Jamaica, Mexico, Puerto Rico, Venezuela.

231. Trichia favoginea (Batsch) Pers., 1794

Recorded in 1, 3 and 4. On BW, GL, LC. In TWF, MWF, LRF, MRF. Vouchers in M, UARKM, CR, USJ, INII. Distribution: Colombia, Costa Rica, Cuba, Dominican Republic, Jamaica, Leeward Islands, Mexico, Panama, Puerto Rico, Trinidad and Tobago, Venezuela, Windward Islands.

232. Trichia flavicoma (Lister) Ing, 1967

Recorded in 6. On GL. In TDF. Vouchers in M. Distribution: Costa Rica, Dominican Republic, Mexico.

233. Trichia lutescens (Lister) Lister, 1897

Recorded in 4. On BW. In LWF. Vouchers in USJ. Distribution: Costa Rica, Mexico.

234. Trichia persimilis P. Karst., 1868

Recorded in 1 and 4. On BW, GL, DU. In LRF, MRF. Vouchers in M, USJ. Distribution: Costa Rica, Mexico, Panama.

235. Trichia scabra Rostaf., 1875

Recorded in 1 and 4. On BW, GL. In LRF, MRF. Vouchers in M, CR. Distribution: Colombia, Costa Rica, Jamaica, Mexico, Venezuela.

236. Trichia varia (Pers. ex J.F. Gmel.) Pers., 1794

Recorded in 3. On BW. In TWF. Vouchers in UARKM. Distribution: Costa Rica, Cuba, Jamaica, Mexico, Venezuela.

237. Trichia verrucosa Berk., 1859

Recorded in 1, 3 and 4. On BW, GL. In LWF, LRF, MRF, SRP. Vouchers in F, M, UARKM, CR, USJ. Distribution: Colombia, Costa Rica, Cuba, Jamaica, Mexico, Windward Islands.

238. Tubifera casparyi (Rostaf.) T. Macbr., 1899

Recorded in 2 and 3. On GL, LC. In TWF, PWF. Vouchers in UARKM, INII. Distribution: Costa Rica, Mexico.

239. Tubifera corymbosa Leontyev, Schnittler, S.L. Stephenson \& L.M. Walker, 2015

Recorded in 4. On GL. In TWF. Vouchers in UARKM. Distribution: Costa Rica, Mexico. Reported from Costa Rica by Leontyev et al. (2015).

240. Tubifera ferruginosa (Batsch) J.F. Gmel., 1792

Recorded in 1, 3 and 6. On BW, GL. In TMF, PMF, TWF, PRF, MRF, SRP. Vouchers in M, UARKM, USJ, INII. Distribution: Costa Rica, Dominican Republic, Jamaica, Leeward Islands, Mexico, Panama, Puerto Rico, Windward Islands.

241. Tubifera microsperma (Berk. \& M.A. Curtis) G.W. Martin, 1947

Recorded in 1, 5, 6 and 7. On BW, GL. In TDF, TMF, PWF. Vouchers in M, UARKM, USJ, INII. Distribution: Colombia, Costa Rica, Cuba, Jamaica, Leeward Islands, Mexico, Nicaragua, Panama, Puerto Rico, Trinidad and Tobago, Venezuela, Windward Islands.

242. Willkommlangea reticulata (Alb. \& Schwein.) Kuntze, 1891

Recorded in 1, 3 and 5. On GL. In TMF, PMF, TWF, PWF. Vouchers in INII. Distribution: Belize, Costa Rica, El Salvador, Honduras, Mexico, Panama, Venezuela. 


\section{Myxomycetes previously included in the list of species of Costa Rica and excluded in the present paper.}

1. Arcyria oerstedii Rostaf., 1875

This species had been reported by ML Farr (1976) based on collection USJ187 (also written as CR187). However, the collection seems to be missing from the TEX herbarium after several transfers. Identification was originally considered doubtful.

2. Badhamia cinerascens G.W. Martin, 1932

This species had been reported by ML Farr (1976) based on collection USJ13 (also written as CR13) with duplicate voucher in University of Texas at Austin number TEX2105. The vouchers seemed to have disappeared after several transfers. Identification was considered doubtful by ML Farr.

3. Cribraria minutissima Schwein., 1832

This species had been reported by CJ Alexopoulos (1975) based on collection USJ91 (also written as CR91) with duplicate vouchers in University of Texas at Austin number TEX852. The vouchers seemed to have disappeared after several transfers. Identification was considered doubtful by CJ Alexopoulos.

4. Comatricha suksdorfii Ellis \& Everh., 1884

This species had been reported by Rojas et al. (2017) based on collections made in Bagaces. However, after later revision of vouchers, errors were observed on specimen identifications, which corresponded to C. tenerrima and Stemonitopsis hyperopta instead of C. sukdorfii. Corrections were made.

5. Diderma niveum (Rostaf.) E. Sheld., 1895

This species had been reported, as Chondrioderma niveum Rostaf., based on a collection identified by C.L. Spegazzini (1919) from Turrialba (Tuis), and deposited in the LP herbarium. However, based on the description of the material and the bioclimatic characteristics of the area of Turrialba, this case was considered a misidentification.

6. Physarum albescens Ellis ex T. Macbr., 1922

This species had been reported by Rojas et al. (2017) based on collections made in Palo Verde National Park. However, after later revision of all vouchers, errors were observed on specimen identifications, which corresponded to Ph. album instead. Corrections were made.

7. Physarum tessellatum G.W. Martin \& M.L. Farr

This species had been reported by Farr (1976) based on a collection deposited in the BPI herbarium (BPI 810391). However, the deposited voucher has been revised and identified as Ph. didermoides by ML. Farr.

8. Reticularia jurana Meyl., 1908

This species had been reported by Rojas et al. (2010a) based on a collection identified by M Schnittler and apparently deposited in the $\mathrm{M}$ herbarium. However, primary information was missing, and the collection does not appear in current databases.

\section{Discussion}

It is remarkable to observe that 242 species of myxomycetes have been reported from Costa Rica, a territory encompassing $51100 \mathrm{~km}^{2}$. As a comparison, 123 species have been reported for Cuba, a country about double the size of Costa Rica (Camino et al. 2008, Lado \& Wrigley de Basanta 2008). Even though relative numbers of species present in selected territories vary with effort and sampling techniques, documented species richness is always valuable to understand the effect of local surveys on regional assessments. For instance, both the Mesoamerican and the Caribbean Biodiversity Hotspots, where Costa Rica and Cuba are located have been unevenly studied and yet the high numbers of species of myxomycetes present in these areas are based on geographically-centered efforts in these countries.

In this sense, the work presented herein directly addressed the Wallacean shortfall (see Hortal et al. 2015) and contributes to the regional assessment of myxomycete distribution within a biodiversity hotspot. For management purposes, this information is relevant to understand the 
dynamics of microbial diversity in ecosystems (i.e., Mittal et al. 1990), with direct implications on subsequent regional species monitoring, for example. Within this context, updated checklists, particularly of microbial groups, have the potential to be used in ecosystem service and ecological dynamics applications.

Interestingly, the important lesson from the province and canton-based analyses carried out in this study is that the utility of scale and survey effort to quantify myxomycete diversity, still fall short for biologically meaningful analyses in Costa Rica. These two concepts should be methodologically addressed in future ecological design of experiments on myxomycetes for this country. These organisms clearly move across human-made borders and distributional analyses based on administrative jurisdictions are superfluous. Despite that, this type of result is also very relevant to define future research lines, unified conservation approaches and human-nature integration, which in the Costa Rican case, are carried out at the canton level. In this sense, the lesson from this analysis is that the integration between biological data and administrative policies should be addressed to avoid traditional shortcomings of political disconnection of research (see Cantú-Salazar \& Gastón 2013) and make data useful for functional assessment purposes. For this reason, even though analyses within administrative boundaries may not be useful for biological purposes, they are highly relevant for management reasons.

The absence of high correlations between province and canton size and the diversity estimators calculated in this study simply demonstrated that the effort has not been standard across those administrative areas. This was also observed in the Shannon's Diversity Index values, which were higher in the provinces of San José and Guanacaste as well as in the cantons of La Cruz, Perez Zeledón, Puntarenas and Sarapiquí. All those administrative areas are among the most studied at their respective level with the previous works of Schnittler \& Stephenson (2000), Rojas \& Stephenson (2007) and Walker et al. (2015b). In this sense, even though some of these results were easy to conclude without a numerical analysis, they also showed (Figs 2-3), where the informational gaps are in Costa Rica, and indicated where to place collecting efforts in the future.

One particularly interesting result was observed in Figs 4-5, where the highest average values of the calculated Shannon's Index of Diversity were associated with the Southern Pacific region, the Talamanca or Guanacaste Mountains and smaller locations along the northern border of Costa Rica. In a similar manner to the previous administrative level-based analysis, these results are likely skewed by survey locations and effort. For instance, in both cases, the seasonal forests of the Nicoya Peninsula and the northern coastline of the Nicoya Gulf, as well as the inner sections of land entering the Central Valley yielded low values of the Shannon's Index of Diversity. Based on results from other heavily seasonal locations (i.e., Estrada-Torres 2015 et al.), this result may simply reflect lack of surveys in the seasonal forests of Costa Rica. As mentioned before, the southern portion of the Alajuela province as well as the locations surrounding the Nicoya Peninsula and Gulf are undersampled (see Fig. 3). Interestingly, even though some areas in the Caribbean are similarly undersampled, results from the Shannon's Index of Diversity analysis at bioclimatic level (Figs 4-5) reflect this result in a different manner.

The $\beta$-diversity analyses showed a similar pattern of survey effort association. The most similar regional-to-local ratios of species richness were found for province or canton pairs with even species richness within the same probability group. This result suggests that the sampling scheme used to generate the data may be responsible for these results and that they do not represent objective comparisons. For instance, the provinces of Limón and Alajuela were in a second-tier probability level simply due to their low documented species richness and more limited number of records. As such, they did not have the same objective probability to form pairs in a $\beta$-diversity analysis with well-studied provinces and the results, as expected, did not show these associations. However, since this observation does not really have to do with biological affinity for selected ecosystems or climate zones and it is more related with survey effort, this is another indication that methodologically sound protocols are still necessary for objective comparisons of myxomycete distribution in Costa Rica. 
The same pattern was observed at the canton level analysis. In this case, Puriscal was found to have strong similarity at the regional-to-local ratio of species richness with both Acosta and Jiménez cantons. Interestingly, these three counties are poorly studied (same tier) and mainly represented by common tropical species such as Diderma hemisphaericum, Didymium squamulosum, Lamproderma scintillans and Stemonitis fusca. In this manner, even though the affinity shown in the $\beta$-diversity analysis was backed up by the data, this result is likely more related to survey effort and methodological approaches to study myxomycetes in these cantons, rather than to real biological affinities. A similar pattern was observed for the pair BagacesSarapiquí, two of the best studied cantons in the country and, in this case, within the same tier of probability level due to their high number of species reported.

Despite all the results showing the shortcomings for ecological analysis of the sampling carried out in Costa Rica, the results provided herein also showed a very interesting list of species. As could have been noted in the references provided with the comments to selected species, Costa Rica has been a territory where five new species of myxomycetes have been described in the last seven years (see Leontyev et al. 2014, Leontyev et al. 2015, Moreno et al. 2010, Walker et al. 2014, 2015a). Also, with the recent reports of Craterium muscorum, Dictydiaethalium dictyosporum, Physarina echinocephala and Stemonaria rufipes (Lado et al. 2018), these elusive species were fully documented, and their distributional range largely widened to encompass the Neotropical area. Similarly, the reports of rare higher elevation species such as Cornuvia serpula, Colloderma oculatum and Leocarpus fragilis have been relevant in the last decades. Within the Mesoamerican Biodiversity Hotspot, the presence of these species is interesting from a biogeographical point of view (see Schnittler et al. 2017).

The remarkable characteristic of the updated checklist of Costa Rican myxomycetes has been the detailed examination of records used to generate the primary information. This exercise of information retrieval and standardization has not been a common practice in tropical regions, albeit its importance for distributional analyses and protocol evaluation. In this sense, the information presented herein has been generated to serve as a reference point for regional assessments within the Mesoamerican region and for comparative purposes across biological regions. However, in general, it also shows the potential of tropical areas to host high diversity of myxomycetes.

\section{Acknowledgements}

This project was funded by research activity COOPB20155 from Consejo Superior de Investigaciones Científicas (CSIC) and by the Myxotropic project (CGL2014-52584P) supported by the Government of Spain. Additional support was provided by University of Costa Rica through research program 731-B8-900 and project 570-B8-006 from FEIMA. We acknowledge the assistance from Randall Valverde, Mitzi Campos and Lolita Durán at the University of Costa Rica, and from Juan Carlos Hernández and Carlos de Mier at the Real Jardín Botánico (CSIC).

\section{References}

Agra LANN, Bezerra ACC, Barbosa DI, Costa AAA, Cavalcanti LH. 2014 - URM Mycological Herbarium: revision of the Myxomycetes. Brazilian Journal of Botany 37, 299-313.

Alexopoulos CJ 1967 - Taxonomic studies in the Myxomycetes I. The Genus Macbrideola. Mycologia 59, 103-116.

Alexopoulos CJ, Sáenz JA. 1975 - The Myxomycetes of Costa Rica. Mycotaxon 2, 223-271.

Camino M, Moreno G, Castillo A, Mitchell DW, Minter DW. 2008 - Additions to the myxomycete biota of Cuba. 1. Mycotax on 106, 75-102.

Cantú-Salazar L, Gaston KJ. 2013 - Species richness and representation in protected areas of the Western hemisphere: discrepancies between checklists and range maps. Diversity and Distributions 19, 782-793.

Clark J 2004 - Reproductive systems and taxonomy in the Myxomycetes. Systematics and Geography of Plants 74(1), 209-216. 
Dagamac NH, Rojas C, Novozhilov YK, Moreno G et al. 2017 - Speciation in progress? A phylogeographic study among populations of Hemitrichia serpula (Myxomycetes). PLoS One 12, e0174825.

Estrada-Torres A, Wrigley de Basanta D, Conde E, Lado C. 2009 - Myxomycetes associated with dryland ecosystems of the Tehuacán-Cuicatlán Valley Biosphere Reserve, Mexico. Fungal Diversity 36,17-56.

Estrada-Torres A, Wrigley de Basanta D, Lado C, Rodríguez-Palma MM. 2015 - Cornuvia (Myxomycetes, Trichiales), a new genus for Mexico. Revista Mexicana de Biodiversidad 86, 9-13.

Farr M 1976 - Flora Neotropica Monograph No. 16 (Myxomycetes). New York Botanical Garden, New York.

Hagelstein R 1944 - The Mycetozoa of North America based upon the specimens in the herbarium of the New York Botanical Garden. Lancaster Press, Pennsylvania.

Holdridge LR 1967 - Life zone ecology. Tropical Science Center. San Jose, Costa Rica.

Hortal J, de Bello F, Diniz-Filho JAF, Lewinsohn TM et al. 2015 - Seven shortfalls that Beset large-scale knowledge of biodiversity. Annual Review on Ecology, Evolution and Systematics 46, 523-549.

Izarduy CC, Canton NV, Catania MV, Hladki AI. 2009 - Catálogo de la colección de Myxomycetes depositados en el Herbario Digilio de la Fundación Miguel Lillo. Miscelanea $125,3-27$.

Lado C. 2006-2017 - An on line nomenclatural information system of Eumycetozoa. Real Jardín Botánico, CSIC. Madrid, Spain. http://www.nomen.eumycetozoa.com (accessed 4 December 2017).

Lado C, Eliasson U. 2017 - Taxonomy and Systematics: Current Knowledge and Approaches on the Taxonomic treatment of Myxomycetes. In: Stephenson SL, Rojas C (eds.) Myxomycetes: Biology, Systematics, Biogeography and Ecology. Academic Press, Massachusetts. Pp 205251.

Lado C, Estrada-Torres A, Rojas C. 2018 - New records of genera and species of Myxomycetes (Amoebozoa) from the Neotropics. Checklist (in press).

Lado C, Wrigley de Basanta D. 2008 - A review of Neotropical Myxomycetes (1828-2008). Anales del Jardín Botánico de Madrid 65, 211-254.

Leontyev DV, Schnittler M, Moreno G, Stephenson SL et al. 2014. The genus Alwisia (Myxomycetes) revalidated, with two species new to science. Mycologia 106, 936-948.

Leontyev DV, Schnittler M, Stephenson SL. 2015 - A critical revision of the Tubifera ferruginosa complex. Mycologia 107, 959-985.

Lizárraga M, Moreno G, Escobar-Zapata S. 2015a - Myxomycetes del área urbana de Ciudad Juárez, Chihuahua, México. Boletín de la Sociedad Micológica de Madrid 39, 83-92.

Lizárraga M, Moreno G, Esqueda M, Salazar-Márquez C, Coronado ML. 2015b - Myxomycetes of Sonora (Mexico) 6. Central plains of the Sonoran Desert. Mycotaxon 130, 145-164.

Lizárraga M, Moreno G, Esqueda M, Salazar-Márquez C, Coronado ML. 2015c - Myxomycetes of Chihuahua (México) 4. Central plains of the Chihuahuan desert. Mycotaxon 130(4), 10731101.

Margules CR, Pressey RL, Williams PH. 2002 - Representing biodiversity: data and procedures for identifying priority areas for conservation. Journal of Biosciences 27, 309-326.

Mittal RK, Anderson RL, Mathur SB. 1990 - Microorganisms associated with tree seeds: world checklist 1990. Petawawa National Forestry Institute, Canada.

Montes JR. 2009. Myxomycetes obtenidos en cámaras húmedas a partir de diez sustratos procedentes de los matorrales xerófilos del Bolsón de Mapimí. Thesis, Universidad Autónoma de Tlaxcala. Mexico.

Moreno G, Mitchell D, Rojas C, Stephenson SL. 2010 - A new species of Stemonitis from Costa Rica. Boletín de la Sociedad Micológica de Madrid 34, 231-236. 
Moreno G, Rojas C, Stephenson SL, Singer H. 2009 - A new species of Lamproderma (Myxomycetes) from Costa Rica. Mycological Progress 8(3), 215-219.

Poulain M, Meyer M, Bozonnet J. 2011 - Les Myxomycètes. Tome 1. Guide de détermination. Fédération Mycologique et Botanique Dauphiné-Savoie, France.

QGIS Development Team. 2004-2014 - Quantum GIS Geographic Information System. Open Source Geospatial Foundation Project. http://www.qgis.org (accessed 10 September 2017).

Rojas C, Calvo E. 2014 - Additions to the myxobiota of Central America. Mycosphere 5, 488-495.

Rojas C, Doss RG. 2014 - Does habitat loss affect tropical myxomycetes? Mycosphere 5(5), 692700 .

Rojas C, Herrera N, Stephenson SL. 2012 - An update on the myxomycete biota (Amoebozoa: Myxogastria) of Colombia. Check List 8(4), 617-619.

Rojas C, Lado C, Valverde R. 2015b - First record of the myxomycete genus Colloderma in Central America. Checklist 11, 1716-1721.

Rojas C, Morales RE, Calderón I, Clerc P. 2013 - First records of myxomycetes from El Salvador. Mycosphere 4(6), 1042-1051.

Rojas C, Morales R, Walker LM, Valverde R. 2017 - New records of myxomycetes for Central America and comments on their regional distribution. Journal on New Biological Reports 6 , 63-70.

Rojas C, Rollins AW, Stephenson SL. 2014 - Distribution of myxomycetes among the microhabitats available for these organisms in tropical forests. In: Misra JK, Tewari JP, Deshmukh K, Vágvölgyi C (eds) Fungi from different substrates. CRC Press. Florida, pp 126- 143.

Rojas C, Schnittler M, Stephenson SL. 2010a - A review of Costa Rican myxomycetes (Amebozoa). Brenesia 73-74, 39-57.

Rojas C, Stephenson SL. 2007 - Distribution and ecology of myxomycetes in the high-elevation oak forests of Cerro Bellavista, Costa Rica. Mycologia 99, 534-543.

Rojas C, Stephenson SL, Estrada-Torres A, Valverde R, Morales O. 2010b - New records of myxomycetes from high-elevation areas of Mexico and Guatemala. Mycosphere 1, 73-82.

Rojas C, Stephenson SL, Huxel GR. 2010c - Macroecology of high-elevation myxomycete assemblages in the Northern Neotropics. Mycological Progress 10, 423-437.

Rojas C, Valverde R. 2015 - Ecological patterns of lignicolous myxomycetes from two different forest types in Costa Rica. Nova Hedwigia 101, 21-24.

Rojas C, Valverde R, Stephenson SL. 2015a - New additions to the myxobiota of Costa Rica. Mycosphere 6, 709-715.

Rojas C, Valverde R, Stephenson SL, Vargas MJ. 2010d - Ecological patterns of Costa Rican myxomycetes. Fungal Ecology 3, 139-147.

Rojas C, Zúñiga JM, Stephenson SL. 2015c - Ecological niche modeling of some Costa Rican myxomycetes. Current Research in Environmental and Applied Mycology 5(2), 153-159.

Rojas P. 2017 - La estandarización metodológica en la investigación con mixomicetes: el caso de Costa Rica; IX Latin American Mycological Congress, Universidad Peruana Cayetano Heredia, Lima, Peru.

Salazar-Márquez C, Lizárraga M, Moreno G. 2014 - Myxomycetes de matorral xerófilo del municipio de Juárez, Chihuahua, México. Boletín de la Sociedad Micológica de Madrid 38, $67-77$.

Schnittler M, Dagamac NHA, Novozhilov M. 2017 - Biogeographical patterns in myxomycetes. In: Stephenson SL, Rojas C (eds.) Myxomycetes: Biology, Systematics, Biogeography and Ecology. Academic Press, Massachusetts. Pp 299-331.

Schnittler M, Stephenson SL 2000 - Myxomycete biodiversity in four different forest types in Costa Rica. Mycologia 92, 626-637.

Spegazzini CL. 1919 - Fungi Costaricenses nonnulli. Boletín de la Academia Nacional de Ciencias Córdoba 23, 541-609. 
Walker LM, Moreno G, Stephenson SL. 2014 - A new species of Macbrideola from Costa Rica. Boletin de la Sociedad Micológica de Madrid 38, 63-66.

Walker LM, Leontyev DV, Stephenson SL. 2015a - Perichaena longipes, a new myxomycete from the Neotropics. Mycologia 107, 1012-1022.

Walker LM, Rojas C, Stephenson SL. 2015b - The myxomycetes of La Selva Biological Station. Austrian Journal of Mycology 24, 99-111.

Whittaker RH. 1960 - Vegetation of the Siskiyou Mountains, Oregon and California. Ecological Monographs 30, 279-338. 